\title{
Review
}

\section{The pathogenesis of bornaviral diseases in mammals}

\author{
Ian Tizard*, Judith Ball, George Stoica and Susan Payne \\ Department of Veterinary Pathobiology and the Schubot Exotic Bird Health Center, Texas A\&M \\ University, College of Veterinary Medicine and Biomedical Sciences, College Station, Texas \\ 77843, USA
}

Received 1 February 2016; Accepted 21 April 2016;

First published online 23 May 2016

\begin{abstract}
Natural bornavirus infections and their resulting diseases are largely restricted to horses and sheep in Central Europe. The disease also occurs naturally in cats, and can be induced experimentally in laboratory rodents and numerous other mammals. Borna disease virus-1 (BoDV-1), the cause of most cases of mammalian Borna disease, is a negative-stranded RNA virus that replicates within the nucleus of target cells. It causes severe, often lethal, encephalitis in susceptible species. Recent events, especially the discovery of numerous new species of bornaviruses in birds and a report of an acute, lethal bornaviral encephalitis in humans, apparently acquired from squirrels, have revived interest in this remarkable family of viruses. The clinical manifestations of the bornaviral diseases are highly variable. Thus, in addition to acute lethal encephalitis, they can cause persistent neurologic disease associated with diverse behavioral changes. They also cause a severe retinitis resulting in blindness. In this review, we discuss both the pathological lesions observed in mammalian bornaviral disease and the complex pathogenesis of the neurologic disease. Thus infected neurons may be destroyed by T-cell-mediated cytotoxicity. They may die as a result of excessive inflammatory cytokine release from microglia. They may also die as a result of a 'glutaminergic storm' due to a failure of infected astrocytes to regulate brain glutamate levels.
\end{abstract}

Keywords: Bornavirus, encephalitis, microglial activation, astrocytes, glutamate, excitotoxicity, mammals.

\section{Introduction}

Bornaviruses have long been known to cause meningoencephalitis in horses and sheep in parts of Central Europe (Metzler et al., 1976; Durrwald and Ludwig, 1997; Richt et al., 2000). Subsequent studies have demonstrated that they induce a similar disease in experimentally infected laboratory rats and mice (Narayan et al., 1983a, b; Kao et al., 1984). The course of the rodent disease is however dependent upon age, such that adult rats develop an acute encephalitis while newborns develop multiple neurodevelopmental disorders. Other bornavirusinfected rodents such as gerbils fail to show these age-related differences. Additionally, a bornavirus from variegated squirrels (Variegated squirrel bornavirus, VSBV-1) can cause an acute lethal encephalitis in humans (Hoffmann et al., 2015). More

*Corresponding author. E-mail: itizard@cvm.tamu.edu significantly, it was believed for many years that bornaviruses contributed to human mental illness (Bode and Ludwig, 2003). This concept has been largely discredited. In contrast, avian bornaviral infection of parrots and waterbirds results in proventricular dilatation disease as well as encephalitis (Honkavuori et al., 2008; Kistler et al., 2008; Rubbenstroth et al., 2014). An uncharacterized bornavirus also appears to cause a naturally occurring acute paralytic syndrome in ostriches (Malkinson et al., 1993; Ashash et al., 1996). The goal of this review is to provide an overview of the pathogenesis of bornavirus-mediated neurologic disease in mammals in light of these recent findings.

\section{Bornaviruses}

Bornaviruses (order Mononegavirales family Bornaviridae, are enveloped non-segmented, single stranded, negative sense 
RNA viruses whose prototype member is Borna disease virus 1 (BoDV-1) (Lipkin et al., 2011). BoDV-1 primarily infects mammals but has been detected in birds (Malkinson et al., 1993; Berg et al., 2001). Bornaviruses have a unique genome organization among the Mononegavirales. The $8.9 \mathrm{~kb}$ genome contains six open reading frames that encode six viral proteins, N, P, M, $G$ and $L$ plus a small $X$ protein that overlaps the $P$ reading frame. To maximize the use of the genome, BoDV-1 employs the RNA splicing machinery for gene expression (Cubitt et al., 1994; Schneider et al., 1994). Three transcription start sites and four termination sites have been identified as well as the use of splicing to generate additional mRNAs (Schneemann et al., 1994; Ludwig, 2008). N, P and L proteins together with the viral RNA form a ribonucleoprotein (RNP) complex (Fig. 1). Once within the cytoplasm, the RNP complex translocates into the nucleus (Jamali et al., 2011; Honda and Tomonaga, 2013). Viral replication and transcription occur within the nucleus. Only a small number of infectious particles are released from bornavirus-infected cells (Gonzalez-Dunia et al., 1998; Tomonaga et al., 2002).

For many years, BoDV-1 was the only known member of the Bornaviridae. It shows little genetic variation with $4.1 \%$ diversity in nucleotides and $1.5-3 \%$ diversity in the amino acid sequences of its N- and P-proteins (Formella et al., 2000; Lipkin et al., 2011). The finding of multiple bornavirus species in parrots in 2008 changed that situation. Thus the known Bornaviridae have expanded from a single conserved mammalian virus to a highly diverse family of at least six viral species (Kuhn et al., 2015). Mammalian 1 bornavirus encompasses classical Borna disease virus- BoDV-1 and BoDV-2. Recently, VSBV-1 has been identified and may be a new species. Parrot 1 bornavirus encompasses psittacine bornaviruses 1, 2, 3, 4 and 7; Parrot 2 bornavirus, encompasses psittacine bornavirus 5; Passeriform 1 bornavirus (canary bornaviruses); Passeriform 2 bornavirus (estrilidid finch bornavirus); waterbird 1 bornavirus (aquatic bird bornaviruses -1 and -2) have also been described. At least two bornaviruses have also been identified in snakes (Elapid 1 bornavirus and an unclassified virus) and multiple endogenous bornaviral sequences have been identified in mammals including people (Horie et al., 2010, 2013).

\section{Borna disease in mammals}

Natural Borna disease affects horses and sheep in central Europe. It occasionally affects other domestic mammals such as donkeys, goats and cattle. It has been recorded in rabbits, some zoo animals and dogs (Staeheli et al., 2000). Cases of 'staggering disease' in cats have also been attributed to infection by BoDV-1 (Wensman et al., 2014). It is believed that these naturally occurring cases result from infection acquired from the urine of shrews.

The bicolored white-toothed shrew (Crocidura leucodon) is a reservoir host species for BoDV-1 within endemic regions of central Europe and develops an asymptomatic infection (Sprankel et al., 1978; Puorger et al., 2010; Nobach et al., 2015). Virus can be detected, not only in the brain and other nervous tissues but also in hepatocytes, Leydig cells in the testes and epithelial cells of the respiratory and urinary tracts. Shrews express large amounts of virus in their oral epithelial cells, as well as skin keratinocytes (Durrwald et al., 2014). Infectious virus and viral RNA can be demonstrated in saliva, urine, skin, tears and feces (Nobach et al., 2015). There is also evidence for a wild reservoir of BoDV-1 in bank voles (Myodes glareolus) in northern Europe (Kinnunen et al., 2007, 2013).

\section{Horses}

Naturally occurring Borna disease has been recognized in horses in eastern Germany since the 18th Century. However, it gained notoriety (and its name) when in 1894-1896 it immobilized a regiment of cavalry based in the town of Borna in Saxony (Richt et al., 2000). Equine BoDV-1 infection occurs naturally only in Germany, Switzerland, Lichtenstein and Austria where on average about $12 \%$ of horses are seropositive.

The typical disease course in horses is characterized by an acute encephalitis that develops following an incubation period of 4 weeks to 3 months (Richt et al., 1997). Non-specific clinical findings such as depression (apathy, somnolence, stupor), fever and anorexia precede ataxia. Horses spread their legs or cross them, and support themselves by pressing their head against the manger or wall. Repetitive behaviors including circling, vacuous slow motion chewing and severe tooth grinding may occur. Eventually, the horses become paretic, develop neurogenic torticollis, or blindness, coma and death. Lethality exceeds $80 \%$ (Ludwig and Bode, 2000; Lipkin et al., 2011). Death usually occurs 1-4 weeks after the onset of clinical signs. A chronic recurring form of the disease may develop in up to $10 \%$ of cases and thus some horses may become persistently infected carriers. Serologic surveys indicate that infection without obvious clinical disease is common (Richt et al., 2000).

On necropsy, horses show no gross lesions. Histopathology shows a non-purulent meningoencephalomyelitis with randomly scattered inflammatory foci in the hippocampus and along the central axis including the mesencephalon and the hypothalamus (Fig. 2). These foci consist of extensive lymphocytic perivascular infiltrates involving primarily the gray matter (Rott and Becht, 1995; Bilzer et al., 1996). Most of the inflammatory cells in these foci are $\mathrm{CD} 3+\mathrm{T}$ cells (Caplazi and Ehrensperger, 1998). Of these, CD4+ cells outnumber CD $8+\mathrm{T}$ cells. Natural killer $(\mathrm{NK})$ cells are likely present in the infiltrates as well (Hatalski et al., 1998). Macrophages are fewer and B cells/plasma cells fewer still. Polymorphonuclear leukocytes are rarely present. The highest viral titers occur in the hippocampus and the piriform cortex reflecting viral invasion from the olfactory bulbs. The lowest viral titers are in the cerebellum (Gosztonyi, 2008). The virus is primarily located within neuronal nuclei (Richt et al., 2000). Less consistently, smaller amounts of viral antigen may be detected in the neuronal perikaryon, dendrites and axons (Bilzer et al., 1996). There is usually a correlation between viral titer and the severity of the brain lesions and the inflammatory exudate is associated with the presence of viral antigen, but the inflammatory cells never appear to contain viral 


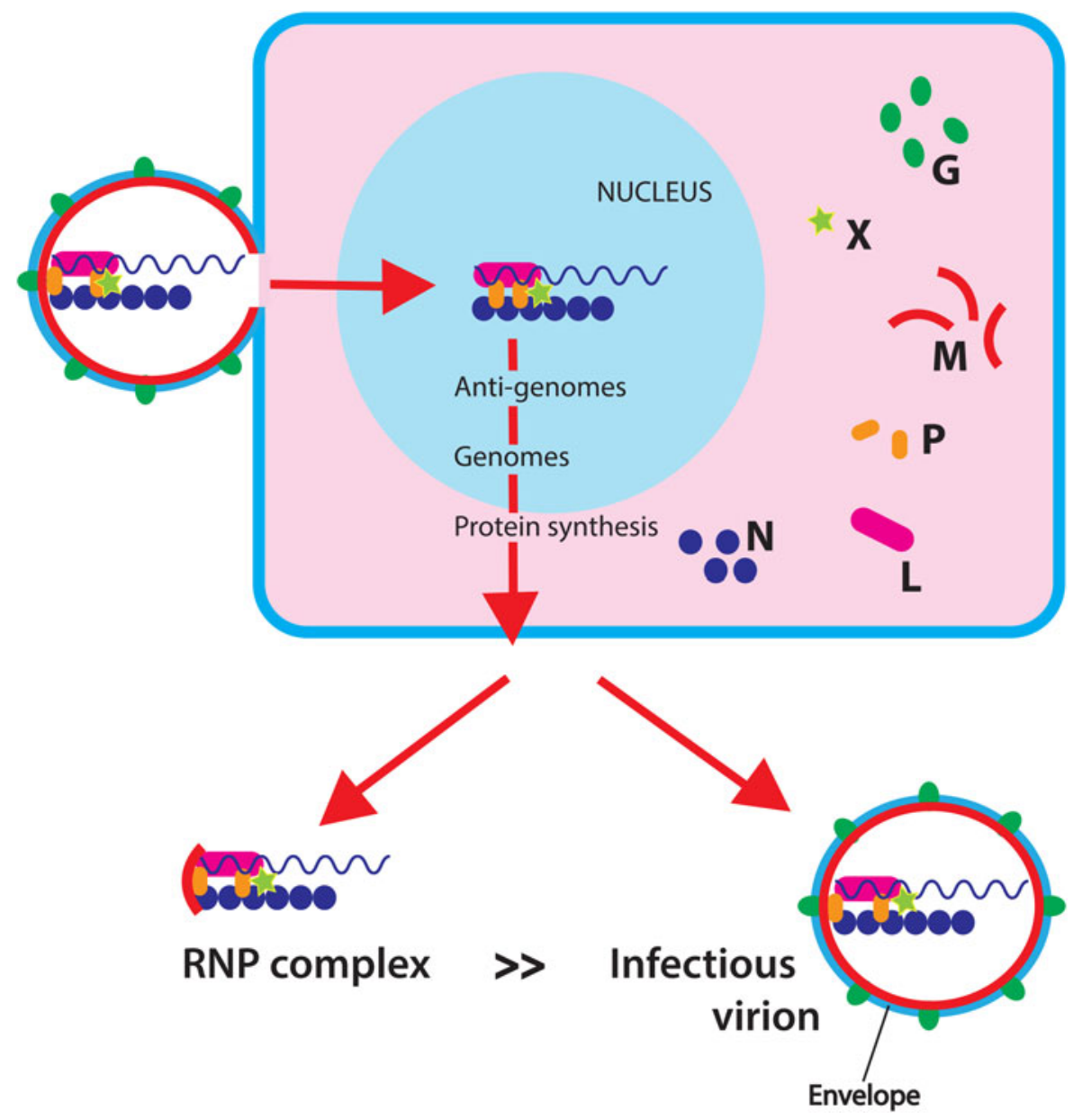

Fig. 1. The intranuclear replication of bornaviruses. The viral ribonucleoprotein (RNP) complex is imported into the nucleus. It binds to the nuclear chromatin and generates more of these RNP complexes. The virus rarely forms complete virions and as a result, it probably spreads between cells in the form of the RNP.

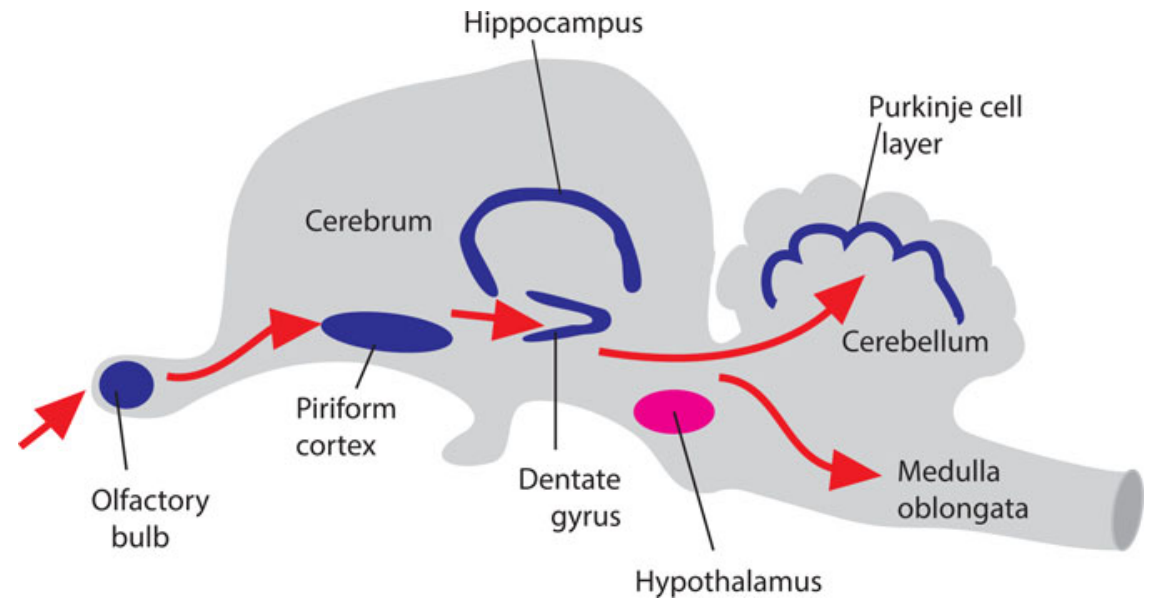

Fig. 2. The major sites within the equine brain that BoDV-1 appears to favor. Infected neurons are also scattered diffusely throughout the cerebrum. The arrows indicate what is believed to be the 'natural' route of viral invasion, originating in the olfactory bulb. 
antigens (Gosztonyi and Ludwig, 1984). In chronic infections, viral antigen is demonstrable in astrocytes and the meningeal surface is infiltrated with mononuclear cells (Richt et al., 2000). Inflammation may spread from the gray matter into the adjacent white matter and involve nerve roots and the spinal ganglia (Johnson, 1980).

\section{Sheep}

Natural Borna disease in sheep resembles that in horses although large numbers of sheep may be affected within a flock unlike horses where the disease usually affects few animals (Richt et al., 1997). Clinical signs vary from minor behavioral changes to severe encephalomyelitis reflecting the intensity of the inflammatory response in the brain (Vahlenkamp et al., 2002). A short period of depression precedes overt disease including somnolence, ataxia and multiple deficits (Metzler et al., 1976; Waelchli et al., 1985). As in horses, the majority of BoDV-1 infections in sheep remain asymptomatic. The location of the virus within the brain is identical to that in horses. Lethality in clinically affected animals is at least $50 \%$. Some sheep recover completely while others survive but fail to thrive (Metzler et al., 1979).

\section{Cats}

BoDV-1 causes staggering disease in cats (Lundgren et al., 1995b; Wensman et al., 2014; Lutz et al., 2015). This begins with fever, apathy and a reduced appetite. Cats eventually develop ataxia, gait disturbances, blindness, lower back pain, behavioral changes, loss of postural reactions and hind-leg paralysis (Wensman et al., 2014). Some may be unable to retract their claws (Lutz et al., 2015). A similar disease can be induced by experimental challenge with BoDV-1 (Lundgren et al., 1997). Some cats recover. There are anecdotal reports of cats surviving the acute infection and later developing extreme obesity (Wensman et al., 2014). The lesions in the cat brain are similar to those observed in horses although plasma cells may be more prominent (Lundgren et al., 1997). While it is possible that cats become infected by eating small infected mammals or birds (Berg et al., 2001) it is just as likely that it results from exposure to the urine of infected shrews (see below). It has been suggested that as in horses and sheep, the virus probably enters the cat through the olfactory epithelium and the oropharyngeal mucosa and then gains access to the brain by intraaxonal spread (Wensman et al., 2014).

BoDV-1 triggers an intense $\mathrm{T}$ cell reaction in the cat brain. Lundgren et al. observed elevated $\mathrm{T}$ cell numbers in the blood and brains of experimentally challenged cats (Lundgren et al., 1995a, 1997). Berg et al. used flow cytometry to demonstrate that the CD8+ $\mathrm{T}$ cells in the brain of infected cats belong to a non-major histocompatibility complex (MHC) restricted population and suggested that they could be important in viral clearance from neurons (Berg et al., 1999). Some cats may develop disease in the absence of gross encephalitis, a disease process similar to that seen in neonatal rats (See below). Infected cats express high levels of interferon (IFN)- $\gamma$ in their brains and this may promote $\mathrm{NK}$ and $\mathrm{T}$ cell cytotoxicity and neuronal destruction (Wensman et al., 2011, 2014). However BoDV-1 can survive in the presence of IFN- $\gamma$ (Wensman et al., 2014). CD8 + cells stimulated by BoDV-1 are found in blood, spleen and brain. Cats may also develop inflammatory changes in their intra-abdominal ganglia and the adrenal medulla (Wensman et al., 2012).

\section{Humans}

At least one bornaviral species can infect humans. In 20112013, three breeders of variegated squirrels (Sciurus variegatoides) in Germany developed a progressive meningoencephalitis and died within 2-4 months (Hoffmann et al., 2015). Their clinical disease progressed from a fever, to progressive psychomotor slowing, confusion, ocular paresis, coma and death. On autopsy, their brains showed edema, gliosis, lymphocyte infiltration with perivascular cuffing, and necrosis. Subsequently a bornavirus was isolated from their brains as well as from the brains of one of their squirrels. Sequencing of this virus genome revealed that it was a previously unidentified mammalian bornavirus (VSBV-1). The distribution of virus in the brains of these patients and in the squirrel resembled that seen in equine Borna disease. There was a high viral RNA load in an oropharyngeal swab from the squirrel suggesting that squirrels may act as carriers and that the virus may have been accidentally transmitted by squirrel bites (Hoffmann et al., 2015). One of these patients had high levels of autoantibodies to the Yo autoantigen, an antigen located within Purkinje cells. However other authors have considered the presence of these autoantibodies in other viral encephalitides to be a clinically irrelevant epiphenomenon (Jarius and Wildemann, 2015).

In 1985, it was suggested that Borna disease virus could cause mental illness in humans (Amsterdam et al., 1985). Thus Rott et al. using an indirect immunofluorescent focus assay, detected antibodies to BoDV-1 in 16 out of 979 psychiatric patients but none were found in 200 normal volunteers (Rott et al., 1985). $\mathrm{Fu}$ et al. also reported that patients with mental illness had antibody titers against BoDV-1 (Fu et al., 1993). These, and subsequent reports stimulated extensive investigations into possible links between bornaviral infection and mental health. It was suggested that BoDV-1 was associated with human neuropsychiatric diseases including bipolar disorder, chronic fatigue syndrome, schizophrenia and unipolar depression. However, isolation of BoDV-1 from humans is rare, and the serologic results obtained are possibly mis- or over-interpreted (Lipkin et al., 2011). Positive reverse-transcriptase polymerase chain reaction results may have been a result of inadvertent laboratory contamination, because the human-derived sequences showed marked similarity to animal-derived laboratory strains (Durrwald et al., 2007). It is now generally accepted that bornaviruses are not a significant cause of human neuropsychiatric disease (Lipkin et al., 2011; Hornig et al., 2012). 


\section{Rodents}

Experimental BoDV-1 infection of laboratory rats and mice has revealed many key features of bornaviral pathogenesis. One of the most significant features of these infections is the difference between the nature of the disease in adult and newborn rats.

\section{Adult rats}

Experimental infection of immunocompetent adult rats with BoDV-1 results in the development of an encephalitis similar to that observed in horses and sheep. The lesions that develop depend on the age and immune status of animals as well as their genetic background, the route of inoculation and on the passage number of the virus (Wu et al., 2013). Many infected adult rats die within 1-4 months as a result of the encephalitis but $50-80 \%$ may survive and develop behavioral abnormalities or an obesity syndrome (Hirano et al., 1983; Narayan et al., 1983a).

BoDV-1-inoculated adult rats develop illness after an incubation period of 17-90 days, the time required for the virus to spread in dendritic-axonal processes from the inoculation site to the hippocampus (Carbone et al., 1987). Intranasal inoculation of virus results in spread to the olfactory bulb by $4-6$ days, and to the rest of the brain in 20 days. Inoculation into the footpads results in intraaxonal spread towards the brain. The virus then migrates from the dorsal root ganglia adjacent to the lumbar spinal cord, to the gracilis nucleus in the medulla, the pyramidal cells in the hippocampus and eventually, results in clinical disease. This progression takes 50-60 days (Carbone et al., 1987). Intravenous inoculation of rat foot veins fails to cause infection suggesting that the virus does not cross the vascular endothelium (Carbone et al., 2001). Sectioning of the foot nerve within 1 day of footpad inoculation also prevents viral migration to the brain but not if the nerve is cut later. Once introduced into the rat central nervous system, BoDV-1 persists in the brain and spinal cord (Herzog et al., 1984). In immunocompetent adult rats neither infectious virus nor viral antigens can be detected in lung, spleen, kidney, muscle, peritoneal macrophages or blood leukocytes (Stitz et al., 2002).

Infected adult Lewis rats show increased alertness at 20 days post-infection. Eventually this develops into frenzied behavior (exaggerated motor responses to minor stimuli), aggression and ataxia (Narayan et al., 1983a). The onset of these behaviors coincides with the development of encephalitis and retinitis that reaches maximum intensity $30-40$ days after infection. The cessation of this active phase coincides with a decline in inflammation and the onset of blindness and results in a change to a passive behavior with apathy, somnolence and depression. The diminution of inflammation may be associated with the development of static hydrocephalus. By 200 days, there is much virus but minimal inflammation in the brain (Narayan et al., 1983b).

\section{Neonatal rats}

In neonatal rats, experimental infection with BoDV-1 results in transient mild inflammation, and there are no immediate clinical signs of disease. However the virus does cause glial activation that eventually leads to significant changes in brain development, behavioral abnormalities and a life-long persistent infection (Hornig et al., 1999). This infection is initiated at a time when the rat brain is continuing to develop and its neuronal connections are being tuned and adapted to environmental influences (Gonzalez-Dunia et al., 2005). Herzog et al. compared BoDV-1 distribution following challenge in adult and neonatal rats. In adults, the virus was restricted to the central nervous system, but in neonates it was also found in the heart, adrenal, stomach and intestine but not blood (Herzog et al., 1984).

This persistent infection of newborn rats results in selective injury to those areas of the brain undergoing significant postnatal development (de la Torre, 2002). Thus, there is neuronal loss in the cortex, hippocampus and cerebellum (Fig. 3). The lesions in the hippocampus are concentrated in the granule cells of the dentate gyrus. This neuronal degeneration results from progressive granule cell apoptosis (Hornig et al., 1999). Neonatal neuronal plasticity is accompanied by formation of new synapses and an increase in dendritic arborization (Engert and Bonhoeffer, 1999). Synaptic density is altered in BoDV-1infected neonatal rats and in BoDV-1-P transgenic mice (Gonzalez-Dunia et al., 2000; Kamitani et al., 2003)

Eisenman et al. showed reduced cerebellar size but normal lamellar organization in BoDV-1-infected neonatal rats (Eisenman et al., 1999). Gaps eventually develop in the Purkinje cell layer of the cerebellum and it has been estimated that up to $75 \%$ of Purkinje cells may be lost in these animals (Bautista et al., 1995; Eisenman et al., 1999).

Persistently infected neonatal rats also develop an astrocytosis (Ovanesov et al., 2008a). These astrocytes control homeostasis around synapses and have a key role in removing excess neurotransmitters such as glutamate (Coulter and Eid, 2012). Bornavirus-infected astrocytes have a reduced ability to take up glutamate (de la Torre, 2002) (see below).

Persistently infected neonatal rats have impaired cognitive functions, and deficiencies in fear conditioning (Carbone et al., 2001; Pletnikov et al., 2002). Despite their cerebellar abnormalities, they do not show ataxia, but they do exhibit noveltyinduced hyperactivity, chronic anxiety and have abnormal sleep-wake cycles, as well as decreased play behavior (Hornig et al., 2001; Pletnikov et al., 2002). These neonatal rat behaviors resembles some human neuropsychiatric disorders especially autism spectrum disorder (Lancaster et al., 2007).

\section{Mice}

The results of experimental BoDV-1 infection in adult mice are strain specific (Rubin et al., 1993). It may result in non-symptomatic infection (Hallensleben et al., 1998) or fatal encephalitis depending on the strain of mice used (Hausmann et al., 1999). For example, $13 \%$ of infected C57BL/ 6 mice show mild transient symptoms. In contrast, $80 \%$ of infected MRL mice develop severe disease although the amounts of virus in their brains are comparable (Rubin et al., 1993). Intracerebral inoculation of BoDV-1 into 32 -Microglobulin-deficient (CD8-) newborn 


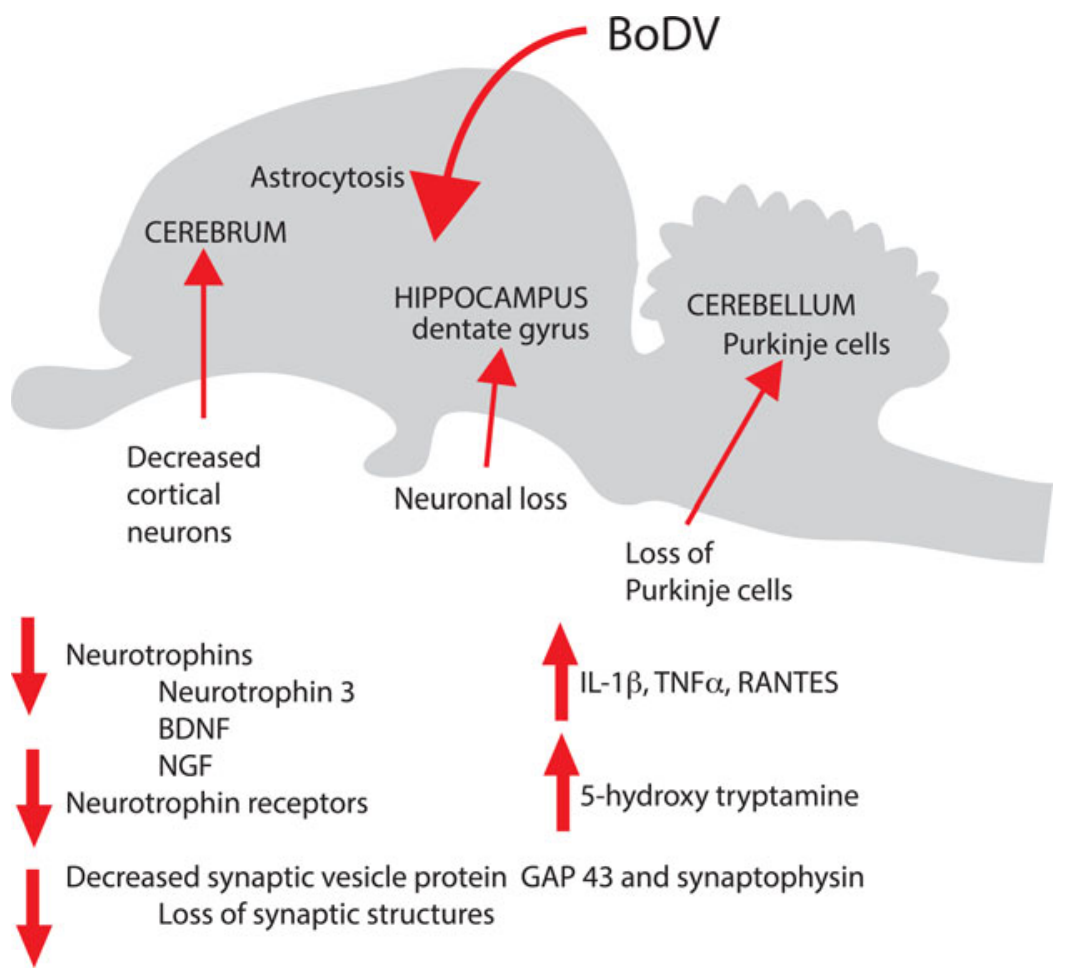

Fig. 3. A schematic diagram showing the multiple alterations in neurogenesis induced by BoDV-1 in neonatal mice.

mice of both strains does not result in disease (Hallensleben et al., 1998).

Ackermann et al. generated a mouse-adapted BoDV-1 that expressed green fluorescent protein, and then infected mice intracerebrally. By 28 days after challenge, labeled astrocytes were detected in the lower hippocampus (the subiculum). Eventually infected neurons were found throughout the hippocampus. The virus was found in Purkinje cells and in the inner granule layer of the cerebellum by day 65 . The virus was also expressed in cerebral neurons and from day 65 onward was found in the neurons of the spinal cord. By day 120 the virus was detectable in the sciatic nerve (Ackermann et al., 2010). BoDV-1 infection of neonatal mice causes neurologic disease 4-6 weeks after intracerebral infection. The animals show abnormal hind leg positioning and eventual paraparesis (Narayan et al., 1983a).

\section{Gerbils}

Experimental BoDV-1 infection of neonatal gerbils (Meriones unguiculatus), unlike neonatal rats, resulted in their death within 30 days. Virus was readily detected in their brains associated with the development of acute inflammatory lesions (Nakamura et al., 1999). Despite severe symptoms and high levels of virus, there was no apparent neuronal loss (Watanabe et al., 2001). In gerbils that had not sickened, the virus was detected in the cerebral cortex and the hippocampus. As disease progressed, viral expression increased in the lower brain stem and cerebellum, especially within Purkinje cells (Watanabe et al., 2001). However while infected newborn gerbils developed fatal neurologic disease those infected 14 days after birth survived (Lee et al., 2003). Very low levels of virus were detected in their brains. Additionally, neonatal gerbils treated with cyclosporine A were not protected against fatal disease. The cyclosporine did however prevent brain inflammation and significantly reduced brain cytokines (except interleukin (IL)-1ß) (Watanabe et al., 2003).

\section{Other species}

BoDV-1 has been used to induce experimental infections in many other mammals. The clinical disease and outcome vary between species. Rabbits, for example, develop a fatal paralytic disease similar to that seen in horses (Richt and Rott, 2001); tree shrews (Tupaia glis) develop aberrant neurologic behaviors (Richt et al., 1992); and rhesus monkeys develop severe paralytic disease with retinopathy (Stitz et al., 1981; Richt et al., 1992). BoDV-1 has been detected in two dogs with neurologic symptoms (Weissenbock et al., 1998; Okamoto et al., 2002). Cattle can also develop Borna disease but it is uncommon and sporadic (Bode et al., 1994; Caplazi et al., 1994). Bornaviral encephalitis has also been recorded in captive alpacas and wild deer (Jacobsen et al., 2010).

\section{The pathogeneses of Borna diseases}

When viruses invade the brain a consistent defensive response is mounted. Thus virus-infected cells are detected by resident 
microglia and recruited macrophages. These responding cells become activated and release a mixture of antiviral cytokines and chemokines (Russo and McGavern, 2015). These cytokines in turn, attract $\mathrm{T}$ cells, NK cells and other mononuclear cells to the site of invasion. Antigen presentation by the antigenprocessing cells, release of cytokines and other mediators from microglia and astrocytes stimulates a type 1 antiviral $T$ cell response (Hatalski et al., 1998). For many, but not all viruses, this $\mathrm{T}$ cell response is sufficient to eliminate the virus. This is not the case in Borna diseases.

\section{Encephalitis}

In BoDV-1 infected rats, the most severely affected brain regions include the olfactory bulb, the dentate gyrus, the caudate nucleus and the hippocampus as well as adjacent structures such as the mesencephalon, central gray matter, substantia nigra and hypothalamus (Tomonaga et al., 2002). BoDV-1 thus exhibits a preferential tropism for the rodent limbic system (de la Torre, 2002). Unfortunately, the viral cellular receptor(s) have yet to be identified, so the biochemical basis of this tropism is unknown.

BoDV-1 enters cells by receptor-mediated endocytosis (Gonzalez-Dunia et al., 1998). The primary route of natural invasion in most mammals is most likely through the nasal epithelium (Morales et al., 1988; Sauder and Staeheli, 2003). The olfactory bulbs of experimentally infected horses show inflammation and edema early in disease (Solbrig and Koob, 2003). The virus replicates in the neurons at the initial entry site and then migrates intra-axonally towards the brain (Carbone et al., 1987; Salinas et al., 2010). The viral surface glycoprotein is required for cell to cell transfer (Bajramovic et al., 2003; Lennartz et al., 2016). The viral RNP complex spreads by axonal and polysynaptic neuronal transmission. Once within the axon, intracellular microtubules transport the viral RNP (Clemente et al., 2010). The protein dynein forms motor complexes with BoDV-1 RNP and transport it from the nerve terminal to the cell body (Gosztonyi et al., 1993; Clemente et al., 2010). Subsequently, RNP spreads to other cells such as astrocytes, oligodendroglia, ependymal cells and possibly Schwann cells. Eventually viral RNA can be detected in all peripheral nerves (Enbergs et al., 2001). As inflammation develops, perivascular cuffs form. These cuffs contain CD4+ and CD8+ $\mathrm{T}$ cells and macrophages (Hatalski et al., 1998).

BoDV-1 is not cytotoxic in cultured cells (Stitz et al., 2002; Matsumoto et al., 2012). The virus is strongly cell associated and produces very few infectious virions per cell even though large quantities of RNP are present (de la Torre, 2002; Tomonaga et al., 2002). Virions are not detected in infected brain either, suggesting that virus spreads as an RNP complex (Zimmermann et al., 1994). Transgenic mice expressing BoDV P-protein in their astrocytes show major behavioral abnormalities such as aggressiveness, hyperexcitability and special reference memory deficit resembling those seen in bornavirusinfected mice (Honda et al., 2011). These behaviors are associated with alterations in the expression of genes associated with the transforming growth factor (TGF) $-\beta$ pathway (Kamitani et al., 2001; Nishino et al., 2015).

$\mathrm{Wu}$ et al. infected hippocampal slice cultures of several rat strains with BoDV-1 (Wu et al., 2013). Cultures from some strains such as Lewis (LEW) showed disrupted architecture while others, such as Sprague Dawley (SD) did not. The efficacy of viral replication was however identical in cultures from different rat strains. These strain differences also occur in vivo. Media harvested from uninfected LEW or SD cultures could prevent BoDV-1-induced damage in LEW cultures. Infection with BoDV-1 reduced the availability of this inhibitory factor in LEW but not SD cultures. Genetic analysis indicated that a bornaviral resistance locus is present on rat chr6q16 and a susceptibility locus on chr3q21-23 (Wu et al., 2013).

\section{Retinitis}

BoDV-1 spreads to the retina from the brain along the optic nerve. Krey et al. blocked the optic nerves of rabbits by xenon coagulation and then infected them intracerebrally with BoDV-1 (Krey et al., 1979). Retinopathy did not develop, and viral antigen could not be detected in animals with blocked nerves. Blindness is regularly observed in equine Borna disease as a result of retinal degeneration with lymphoplasmacytic infiltration (Bilzer et al., 1996). Lymphocytic infiltrates may also be observed within the optic nerve. There is a great diversity in its severity, and not all horses have detectable bornavirus in their retinas (Dietzel et al., 2007).

Muller cells are retinal glial cells (Kacza et al., 2000, 2001). The neuron:Muller cell ratio in the retina is significantly reduced in diseased horses as compared with controls. This appears to be due to a concomitant loss of neurons and an increase in glia. The neuronal degeneration begins in the outer retinal layer where the photoreceptors are located but all retinal layers show reduced thickness (Kacza et al., 2000).

Neurons are also lost in the retinas of BoDV-1 infected rats and rabbits (Narayan et al., 1983b). Four weeks after intracerebral inoculation of rats there is a significant thinning of the retina due to a loss of photoreceptor segments and ganglion cells. At the same time, there is a great increase in the number of glial cells in the ganglion cell and inner plexiform layers (Kacza et al., 2000). Microglia and macrophages are involved in the neuronophagocytosis that accompanies this neurodegeneration (Kacza et al., 2000). Muller cells show moderate changes (Iandiev et al., 2006). Kacza et al. infected Lewis rats with BoDV-1 intracerebrally (Kacza et al., 2001). Within months their retinal thickness had declined to a third of that in control animals. Photoreceptor segments were completely destroyed and the number of neurons reduced. There were many active microglia and macrophages undertaking neuronophagocytosis. Muller cells showed signs of gliosis, alterations in glutamate synthetase, altered $\mathrm{K}^{+}$currents and thickened stem processes (Kacza et al., 2001).

Narayan et al. attributed bornaviral retinitis to a transient attack by cytotoxic T cells (Narayan et al., 1983b). For example, Krey et al. treated BoDV-1 infected rabbits with 
immunosuppressive drugs that delayed the onset of retinitis (Krey et al., 1981). The treatment reduced the confluency of the retinal lesions and some treated animals either lacked eye lesions or showed nonprogression. Subsequently, Stahl et al. showed that the retinal T cell infiltration consisted of $\alpha \beta \mathrm{TCR}+, \mathrm{CD} 4+, \mathrm{CD} 8+$ cells (Stahl et al., 2003). B cells were rarely found by Stahl et al. but Hatalski et al. found them to be plentiful (Hatalski et al., 1998). This may reflect the use of different reagents. Cytokine transcripts in affected retinas included raised IL- $1 \beta$, IL- 6 , IFN $\gamma$ and tumor necrosis factor (TNF)- $\alpha$, as well as CXCL10, chemokine ligand (CCL) 2 and CCL4. By day 36 the levels of these transcripts had returned to normal. These cytokines were probably derived from the infiltrating $\mathrm{T}$ cells and NK cells (Sauder and de la Torre, 1999). Chronic bornaviral infections may result from a switch in the brain-infiltrating $\mathrm{T}$ cells from generating a Th1 response to a Th2 response (Hatalski et al., 1998).

\section{Alterations in neurogenesis}

In the developing rodent brain, neurogenesis occurs predominantly in the subventricular zone of the lateral ventricles and the subgranular zone of the dentate gyrus in the hippocampus (Katsumoto et al., 2014). It is unclear how neuronal loss occurs in persistently infected neonatal rats but it is probably due to induced apoptosis (Hornig et al., 1999; Zocher et al., 2000; Ovanesov et al., 2008b). Damage to synaptic structures precedes neuronal loss in persistently infected rats and this may impair trafficking of growth factors (Volmer et al., 2007). Bornaviral-induced disturbances in the neurotrophin system also contribute to this neurodegeneration. Thus Zocher et al. found reduced levels of neurotrophin 3, brain-derived neurotropic factor (BDNF) and nerve growth factor in the hippocampus 14-days post-infection in newborn rats and in the cerebellum by 21 days post-infection (Zocher et al., 2000) (Fig. 3). They also detected reduced levels of neurotrophin receptors in both the hippocampus and cerebellum. Neonatal persistently-infected rats fail to gain weight but lack of nourishment does not account for the brain lesions or the lack of weight gain (Dietz and Pletnikov, 2003). There are increased concentrations of serotonin in the hippocampus of bornavirus- infected neonates (Dietz and Pletnikov, 2003). Hans et al. examined the effect of bornaviral infection on the response of hippocampal neurons to neurotrophin BDNF. Persistent infection blocked BDNF-induced extracellular signal-regulated kinases-1/2 (ERK) phosphorylation even although the expression of the BDNF receptor was normal (Hans et al., 2004). As a result, BDNF-induced expression of synaptic vesicle proteins is blocked, potentially causing defective synaptic organization. Persistently-infected newborn rats show a progressive decline in the expression of synaptic markers (growth-associated protein 43 , a presynaptic membrane phosphoprotein and synaptophysin, a calcium-binding protein found in presynaptic vesicles) followed by a loss of up to $30 \%$ of cortical neurons (GonzalezDunia et al., 2000). This decline in synaptic density and neuronal plasticity occurs primarily within the cerebrum and the hippocampus.

\section{Obesity}

Some adult rats that survive acute BoDV-1 disease begin to overeat and as a result, become obese ((Narayan et al., 1983a; Wensman et al., 2014). Obesity also develops in some persistently infected neonatal rats (Lyons et al., 2002). This uncontrolled appetite may result from damage to hunger control centers in the brain (Nagashima et al., 1992; Gosztonyi and Ludwig, 1995). The neonatal rats develop inflammation in their pituitary stalk (Gosztonyi and Ludwig, 1995). As the obesity syndrome develops, the number of virus-infected cells grows and leads to progressive involution of the hypothalamus as well as vacuolar degeneration of neurons in the hypothalamic paraventricular nucleus. Herden et al. compared the brain lesions of a pathogenic BoDV-1 strain with that of an obesity-inducing strain (Herden et al., 2000). The obesity-inducing-strain lesions were restricted to the septum, hippocampus, ventromedial hypothalamus and amygdala. Herden et al. also examined the levels of neuropeptides in BoDV-1-infected brains and found that expression of melanocyte-stimulating hormone (MSH) was reduced in infected animals (Herden et al., 2000; Herden et al., 2005). $\alpha$-MSH reduces appetite so its deficiency may have an opposite effect and bornaviral obesity could therefore be due to lesions in the melanocortin feeding center within the hypothalamus.

\section{Pathogenic processes}

Three major pathogenic processes collectively cause the neuronal damage associated with bornaviral encephalitis (Fig. 4). Initially, the virus replicates almost exclusively in neurons (Gosztonyi and Ludwig, 1995). This triggers immune-mediated attack by virus specific CD8 $+\mathrm{T}$ cells directed against viral antigens such as bornaviral N-protein or autoimmune attack against neoantigens on the neuronal surface (Amor et al., 2014). In the later stages of infection, the virus infects microglia and astrocytes (Carbone et al., 1991; Gosztonyi and Ludwig, 1995). These plus the results of neuronal destruction leads to the prolonged activation of microglia and a consequent increase in tissue cytokines and reactive nitrogen species (Gonzalez et al., 2014). Thirdly, astrocyte dysfunction due to viral invasion disrupts glutamate regulation. Excess glutamate generated as a result kills neurons through a process called excitotoxicity.

\section{Immune-mediated T cell attack}

The primary mechanism of neuronal damage in bornaviral encephalitis is T cell-mediated neuronal cytotoxicity. These $\mathrm{T}$ cells are activated by viral infection and as a result, mount a type 1 response characterized by the production of both IFN- $\gamma$ and TNF- $\alpha$ (Baruch and Schwartz, 2013). The neurotransmitters glutamine and acetylcholine also favor $\mathrm{T}$ cell activation (Pacheco et al., 2010; Pikor et al., 2015) as do activated Th17 cells (Nouri et al., 2014). 


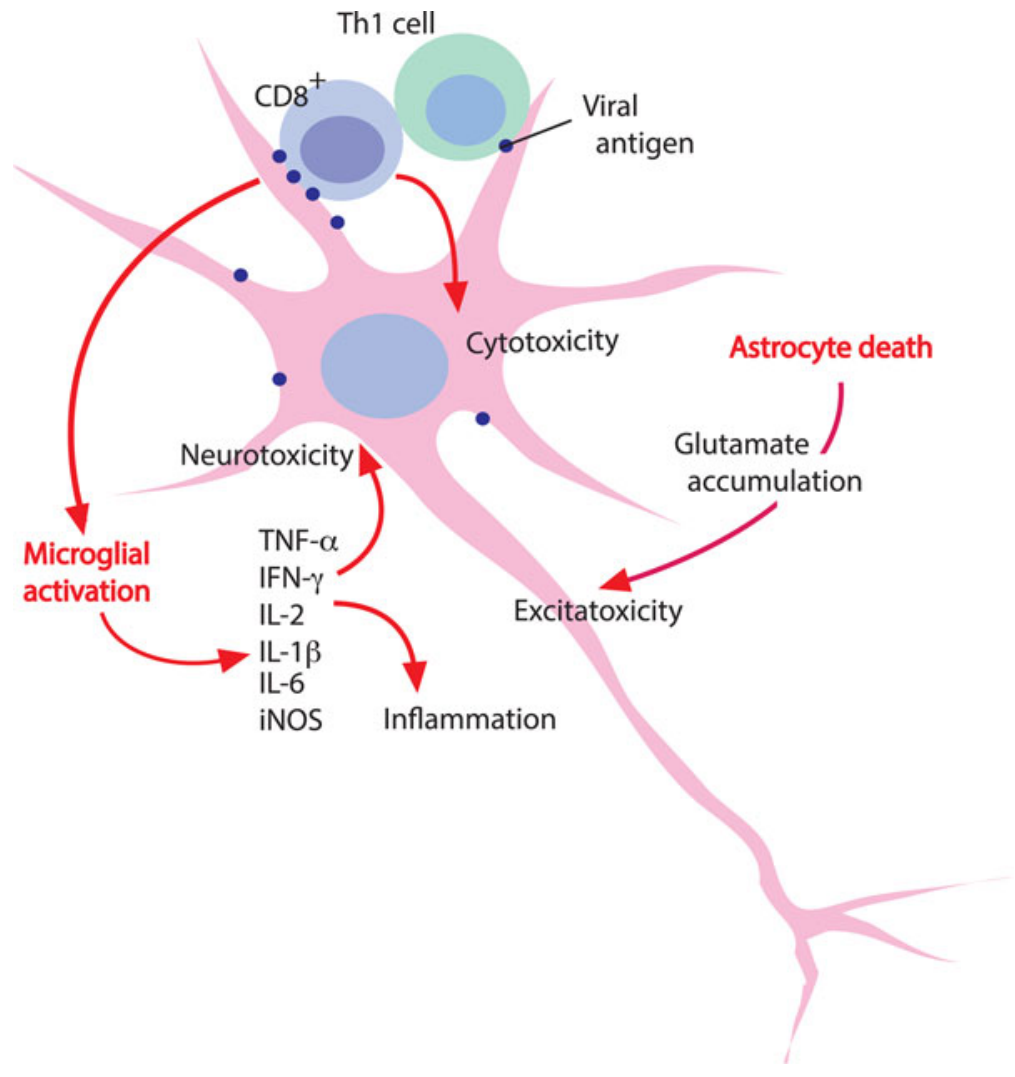

Fig. 4. The three major mechanisms of neuronal destruction mediated by BoDV-1. These are, T-cell-mediated cytotoxicity, microglial activation resulting in cytokine-mediated neurotoxicity, and loss of astrocyte function resulting in glutamate accumulation and excitotoxic destructions of neurons.

In bornaviral lesions, the perivascular cellular infiltrates predominantly consist of CD4+ T cells while CD8+ cells predominate within the brain parenchyma. The development of neuronal lesions is specifically associated with invasion by CD8+ cells (Sobbe et al., 1997). The importance of these T cell infiltrates can be demonstrated by adoptive transfer of lymphocytes from infected to uninfected rats. For example, Narayan et al. could transmit the disease using spleen cells from 4-week-old rats transferred into cyclosporine-treated recipients (Narayan et al., 1983a). Rott et al. were able to establish a virus-specific, $\mathrm{CD} 4+\mathrm{T}$ cell line that induced typical bornaviral lesions when administered to recipient rats of the corresponding MHC class II haplotype (Rott et al., 1988). Sobbe et al. induced typical bornaviral brain lesions in rats by adoptive transfer of CD8+ brain T cells (Sobbe et al., 1997). Additionally, lymphocytes obtained from rats early in bornaviral infection could transfer the disease but not late in infection implying that the cytotoxic cells were generated early in the disease process (Narayan et al., 1983a). Planz et al. identified a peptide, ASYAQMTTY, from BoDV1 nucleoprotein that was recognized by CD8+ T cells in association with the rat MHC class I molecule, RT1.A, and, as a result, triggered T cell cytotoxicity (Planz et al., 2001). Transgenic mice expressing the nucleoprotein are resistant to disease, presumably because they are immunologically tolerant to it (Schwemmle et al., 1998). Lymphocytes from the brains of rats with acute bornaviral disease show MHC class I restricted cytotoxic T cell activity. MHC class I expression occurs on astrocytes and on some neurons in BoDV-1-infected brains. MHC class I production by neurons is normally minimal but can be induced (Planz et al., 1993).

Support for the essential role of $\mathrm{T}$ cells is also provided by immunosuppressive studies. For example, Rott et al. demonstrated that $\mathrm{T}$ cell elimination prevented inflammation and the development of clinical disease. A single intraperitoneal injection of cyclophosphamide given to adult rats prevented the development of bornaviral encephalitis and clinical disease. Stitz et al. were able to prevent the development of bornaviral disease by administering cyclosporine prior to infection (Stitz et al., 1989). Stitz et al. also treated bornavirus-infected adult rats with monoclonal antibodies against $\mathrm{N}$-protein-specific CD4+ and CD8+ T cells (Stitz et al., 1992). Both types of antibody suppressed the encephalitis but anti-CD 8 was more effective than anti-CD4. These monoclonal antibodies worked best if given before or shortly after infection and they did not prevent encephalitis or disease when given more than 4 days after infection. BoDV-1 infection will not result in disease in athymic nude rats (Herzog et al., 1985). Thus the lesions of bornaviral encephalitis in rats are mediated primarily by N-protein-specific CD8+ $\mathrm{T}$ cells.

In persistently infected neonatal rats, unlike adult rats, $T$ cells may be protective. Thus persistent BoDV-1 infection could be prevented by prior administration of a virus-specific CD4+ T 
cell line. Recipient rats developed a transient, mild encephalitis that lasted for only a few days. This $\mathrm{T}$ cell line had no cytotoxic properties but virus clearance was accompanied by the appearance of CD8+ cytotoxic T cells in the recipients (Noske et al., 1998). It is interesting to note however, that in adult rats infected with BoDV-1, the virus is found exclusively in the brain. In cyclosporine-treated rats the virus can be detected in peripheral nerve fibers and adjacent tissues such as lung, liver and spleen (Stitz et al., 1991). This suggests that T cells are responsible for containing BoDV-1 within the central nervous system (CNS). In subsequent studies, Stitz et al. examined the role of antibodies in restricting BoDV-1 to the CNS. Immune serum transfer into cyclosporine-treated or newborn rats resulted in restriction of the virus to the CNS (Stitz et al., 1998).

Hatalski et al. followed the evolution of the immune response in the brain of BoDV-1-infected Lewis rats (Hatalski et al., 1998). Thus at the peak of the acute infection, the perivascular infiltrates contained both CD4+ and CD8 $+\mathrm{T}$ cells as well as a significant population of NK cells. The NK cells could be identified in the brain lesions 3.5 weeks post-infection before the onset of clinical disease. As the disease progressed and became chronic, the numbers of all cell types dropped and the authors suggested that this reflected a switch from a type 1 to a type 2 immune response. This suggestion was supported by a rise in serum IgE levels. Hatalski et al. also measured cytokine mRNA expression in infected brains. They showed a significant increase in the levels of the proinflammatory cytokines, IL- $1 \alpha$, IL-2, IL- 6 , TNF- $\alpha$ and IFN- $\gamma$ that peaked at 5 weeks post-infection when acute inflammation was maximal. On the other hand, the anti-inflammatory cytokine, IL-4 increased to reach maximal levels at the end of the study at 15 weeks. The regulatory cytokine, TGF- $\beta$ in contrast, peaked at 5 weeks and then stabilized (Hatalski et al., 1998). It is possible that the decline in inflammation seen in long-term bornaviral infections may also be due to the development of neuroprotective Treg cells (Walsh et al., 2014). Nishino et al. investigated this upregulation of TGF- $\beta$ in BoDV-1-infected rats. They found that signal receptors for TGF- $\beta 1$ were also upregulated as were inhibitin/activin $\beta C$, two components of the TGF- $\beta$ pathway (Nishino et al., 2009). This may reflect the ongoing immunosuppressive effects of bornaviral P-protein (Nishino et al., 2015).

\section{Microglia and the role of chronic inflammation}

The second important pathogenic process in bornaviral disease results from prolonged activation of microglia (Weissenbock et al., 2000; Ovanesov et al., 2006, 2007, 2008a, b). In the healthy brain, microglia remodel neuronal synapses and secrete neurotrophic proteins that help maintain effective neuronal network functions (Zocher et al., 2000). When activated however, microglia flood the brain with the inflammatory cytokines, TNF- $\alpha$, IFN- $\beta$ and IL-10 as well as induced nitric oxide synthase (iNOS), and reactive oxygen and nitrogen species (ROS and RNS) (Gonzalez et al., 2014). These molecules induce neuronal dysfunction and death (Heneka et al., 2014; Papageorgiou et al., 2015). Zheng et al. have demonstrated that the severity of the neurologic signs and of the corresponding encephalitis correlated well with iNOS and cNOS mRNA expression in rat bornaviral disease and that the distribution of iNOS-positive cells in the basolateral cortex and the hippocampus correlated with sites of BoDV-1 infected cells (Zheng et al., 1993). This cannot however be the whole explanation for bornaviral pathogenicity since Hausmann et al. demonstrated that BoDV-1 caused neurologic disease in mice that lacked IFN- $\gamma$, Fas, iNOS or the chemokine receptor, CXCR3 (Hausmann et al., 2004).

Microglia are activated by BoDV-1 (Plata-Salaman et al., 1999; Ovanesov et al., 2006) (Fig. 5). In BoDV-1-infected adult rats, these activated microglia can be detected in the dentate gyrus at 10 days post-infection but detectable loss of granule cells is not seen until 30 days. Thus the virus activates the microglia long before neuronal loss and it is therefore unlikely that the activated microglia alone trigger neuronal loss and dysfunction (Ovanesov et al., 2008b). Nevertheless, increased levels of brain IL-6, TNF- $\alpha$ and iNOS mRNAs do correlate with the severity of the inflammatory lesions in infected brains (de la Torre, 2002).

Classically activated microglia (M1 cells) have two alternative fates. They may differentiate into regulatory cells (M2 cells) and so reduce inflammation and promote tissue repair or alternatively, they can undergo uncontrolled activation and trigger chronic inflammation resulting in the production of neurotoxic factors and progressive neural loss (Gonzalez et al., 2014). M2 activation of microglia enhances their release of neurotrophic factors, proteases, IL-4, TGF $\beta$ and arginase 1 and stimulates their phagocytic activity. M2 activation thus reduces inflammation and promotes tissue repair. The anti-inflammatory cytokines, IL-4 and TGF $\beta$ are produced during the later stages of bornaviral encephalitis (Hatalski et al., 1998). While they are mainly derived from $\mathrm{T}$ cells, they may also be produced by microglia (Heneka et al., 2014).

Morimoto et al. used dexamethasone to inhibit bornavirusinduced inflammation in rats. They suggested that bornaviral disease involved an early inflammatory reaction mediated by resident microglia leading to sensitization (antigen processing and presentation), and an influx of primed $\mathrm{T}$ cells. Restimulation of these infiltrating $\mathrm{T}$ cells led to the local production of a cytokine mixture amplifying the reaction. Subsequently, recruitment and activation of microglia continued this process. Morimoto et al. suggested that the initial expression of proinflammatory cytokines was directly mediated by microglial BoDV-1 (Morimoto et al., 1996).

\section{Astrocytes and glutamate toxicity}

The third major mechanism of bornaviral-induced neuronal destruction results from astrocyte-mediated disturbances in glutamate levels.

Astrocytes are the major microglial cell population in the brain (Rossi and Volterra, 2009). Under normal conditions, they supply glucose to neurons and regulate the composition of extracellular fluid. Importantly, they remove excess potassium ions and neurotransmitters, especially glutamate (Coulter and Eid, 2012). 


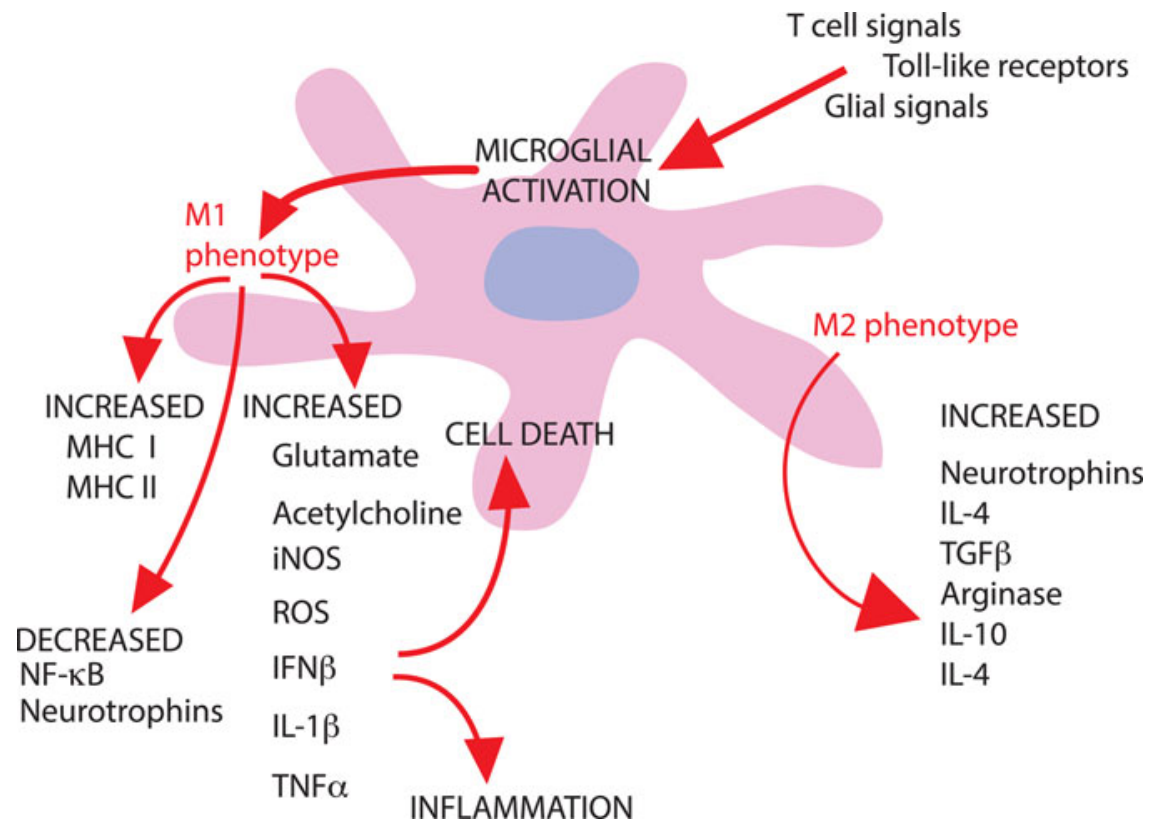

Fig. 5. The role of microglial activation in the pathogenesis of bornaviral encephalitis. M1 activation of the microglia results in the flooding of the brain with multiple cytokines as well as potent oxidants resulting in neuronal death. Should the microglial phenotype change to $\mathrm{M} 2$, the resulting cytokines will reduce inflammation and cell destruction and promote repair although destroyed neurons unlikely to be replaced.

Astrocytes take up extracellular glutamate, transform this into glutamine using glutamine synthetase and subsequently shuttle the glutamine back to neurons using transporters. Between 80 and $90 \%$ of extracellular glutamate uptake in the brain is through these astrocytic glutamine transporters (Vesce et al., 2007; Coulter and Eid, 2012) (Fig. 6). Once within neurons glutamine is reconverted to glutamate. This glutamate may act as a neurotransmitter directly or it is decarboxylated to form $\gamma$-amino butyric acid (GABA), which also acts as a neurotransmitter.

\section{Excitotoxicity}

Excitatory synaptic transmission in the brain is mainly mediated by glutamate (Bondy and Purdy, 1977; Choi, 1988). If the extracellular concentration of glutamate is excessive, neurons will be damaged. This process is called excitotoxicity and the excessive production of glutamate within the brain is called a glutaminergic storm. Neurons die as a result of excessive influx of calcium through glutamate receptor channels leading to mitochondrial damage and the production of ROS and RNS (GudinoCabrera et al., 2014). Excitotoxicity has been associated with neurodegeneration (Jacobs et al., 2006). Excessive glutamate may also impair the blood-brain barrier (Gudino-Cabrera et al., 2014).

In the healthy brain, homeostasis is maintained by the removal of excess glutamate by astrocytes. If these astrocytes are lost and replaced by microglia, the glutamine-glutamate cycle is down-regulated (Schwartz et al., 2003). TNF- $\alpha$ upregulates the production of glutamate in activated microglia and at the same time, inhibits glutamate uptake by astrocytes (Takeuchi et al., 2006).
Billaud et al. showed that BoDV-1 inhibits glutamate uptake by feline primary cortical astrocytes (Billaud et al., 2000; de la Torre, 2002). This failure to remove glutamate could result in neuronal excitotoxicity. This is supported by the studies of Ovanesov et al. who measured extracellular glutamate in the striatum of Fischer 344 rats (Ovanesov et al., 2007). BoDV-1 infection increased the extracellular levels of glutamate. This elevated extracellular glutamate was associated with reduced neuron numbers and volume in the striatum.

Bergmann glial cells are astrocytes that surround Purkinje cells where they sequester neuronally-produced glutamate. Purkinje cells disappear from the cerebellum of BoDV-1infected neonatal mice although they themselves may not be infected. The Bergmann glia are however infected and it is possible that damage to these cells could result in secondary loss of Purkinje cells (Bordey and Sontheimer, 2003).

On the other hand, Richter et al. showed that two glutamate receptor antagonists failed to prevent bornaviral-induced neuronal loss in IFN $\gamma$-deficient mice. While there was a trend towards protection it was not statistically significant. Richter et al. also demonstrated that neither the frequency of virus-infected cells, nor the composition of the $\mathrm{T}$ cell infiltrate was altered by these antagonists and they concluded that glutamate excitotoxicity was an unlikely cause of neuronal damage (Richter et al., 2009). They did not however exclude toxic effects mediated through the third glutamate receptor - kainite. The kainite receptor (KA-1) has been suggested to be a BoDV-1 receptor or target (Gosztonyi, 2008).

Zhang et al. analyzed metabolites in bornavirus-infected areas of the equine hippocampus (Zhang et al., 2014). They found that infected tissues had lower levels of D-myo-inositol-1-phosphate, glutamate, phosphoethanolamine, heptadecanoic acid and 


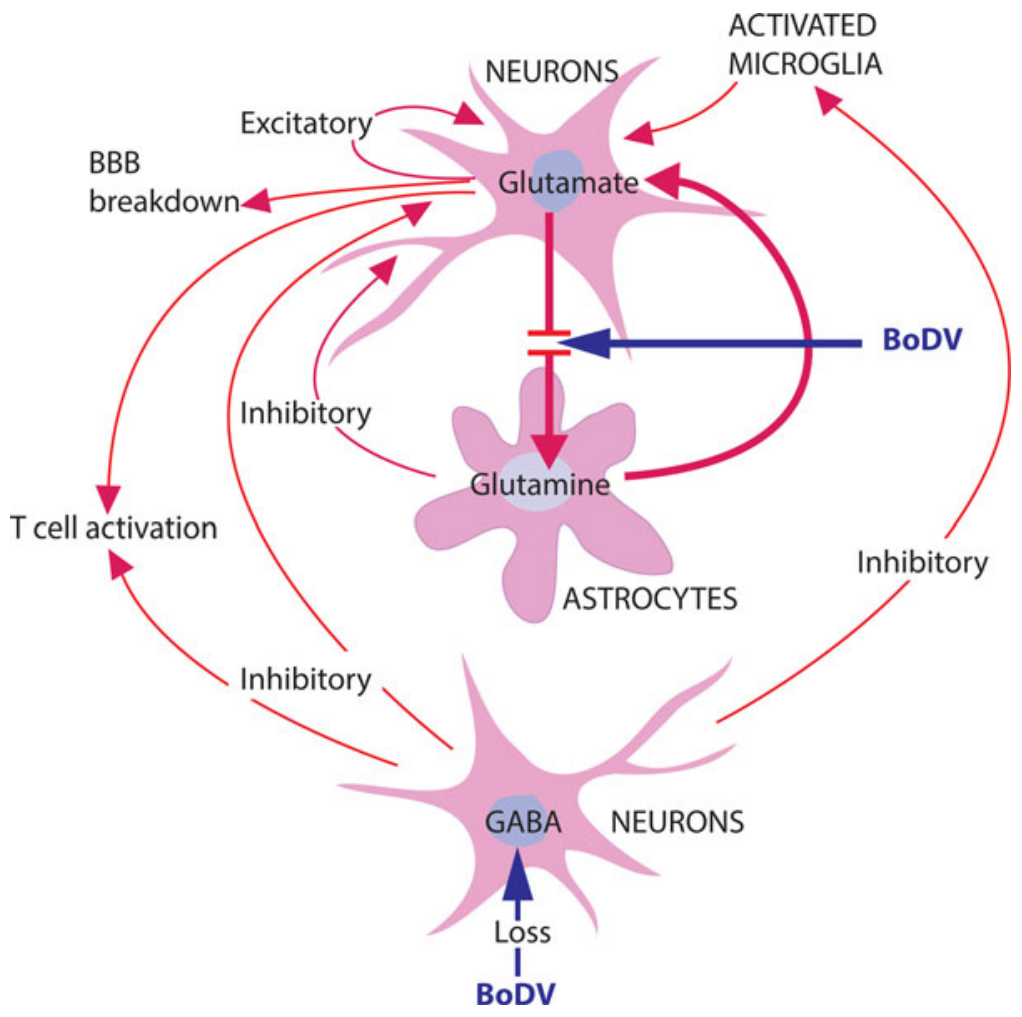

Fig. 6. The role of glutamate in BoDV-1 encephalitis. The normal glutamate cycle requires that astrocytes remove excess glutamate from the extracellular fluid, convert it to glutamine and return it to the neurons. If astrocytes are damaged glutamate accumulates and kills neurons. GABAergic neurons release GABA that inhibits glutamate excitotoxicity and microglial activation. If these neurons are also damaged by BoDV-1 then additional neuronal loss will be expected.

linoleic acid but higher levels of ammonia. These results also confirm that there are disturbances in glutamate metabolism within these tissues.

\section{Effects of glutamate on microglia}

Glutamate release by astrocytes is influenced by inflammatory mediators such as TNF- $\alpha$ and prostaglandins. Thus inflammation may disrupt astrocyte-neuronal interactions (Ovanesov et al., 2008a; Rossi and Volterra, 2009). Activation of microglia by BoDV-1 in vitro requires the presence of astrocytes (Ovanesov et al., 2008a). Activated microglia also release large amounts of glutamate in response to TNF- $\alpha$ by upregulating glutaminase (Takeuchi et al., 2006).

\section{Effects of glutamate on $T$ cell function}

$\mathrm{T}$ cells have receptors for glutamate and glutamate enhances $\mathrm{T}$ cell adhesion, chemotactic migration and proliferation (Schwartz et al., 2003; Levite, 2008). Glutamate also protects them against antigen-induced apoptosis (Ganor and Levite, 2014). Thus glutamate alters surface receptor expression, and may enhance $\mathrm{T}$ cell cytotoxicity. It is possible therefore that elevated glutamate in sites of bornaviral invasion might attract $\mathrm{T}$ cells and promote T-cell-mediated brain damage. It may be relevant to note that many neurotransmitters other than glutamate also activate $\mathrm{T}$ cells (Levite, 2008). For example, resting T cells can also be activated by dopamine, serotonin and some neuropeptides

\section{The role of gamma-aminobutyric acid}

Gamma-aminobutyric acid (GABA) is an inhibitory neurotransmitter synthesized from glutamate using L- glutamic acid decarboxylase. GABA reduces neuronal excitability by acting at inhibitory synapses. GABA also acts as a growth factor for the developing brain where it stimulates neuronal branching (Chen and Kriegstein, 2015). Microglia possess GABA receptors and the GABAergic system can regulate microgial activities. These microglia in turn may regulate GABAergic transmission by neighboring neurons. $\mathrm{T}$ cells and dendritic cells contain glutamic acid decarboxylase and express GABA receptors. GABA also suppresses both proinflammatory cytokine production and immune cell proliferation. Thus an increase in GABA may suppress $T$ cell function and inflammation (Peng et al., 2008).

Bornaviral P-protein binds directly to GABA-receptor-associated protein (Peng et al., 2008). It is then transported to the cell nuclei where it disrupts the trafficking of GABA-receptors (Scordel et al., 2015). The P-protein also reduces neurogenesis, and specifically targets GABAergic neurogenesis. This results from inhibition of the production of pro-neuronal factors 
such as ApoE, Noggin, TH and Scg10/Strathmin2. BoDV-1 can disrupt the GABA-glutamate cycle reducing its inhibitory effect and thus enhancing excitotoxicity and $\mathrm{T}$ cell activity (Fig. 6). Neonatal rats persistently infected with BoDV-1 undergo a selective loss of GABAergic cortical neurons (Bautista et al., 1995; Eisenman et al., 1999; Gonzalez-Dunia et al., 2000; Pletnikov et al., 2002). It is perhaps no coincidence that aberrations in GABAergic neurogenesis have been associated with human neuropsychiatric disorders (Scordel et al., 2015).

\section{Other effects on neurotransmission}

Bornaviral encephalitis in Lewis rats is associated with a decline in the cholinergic activity of the brain (Gies et al., 1998, 2001). This decline appears to be due to a loss of choline acetyltransferase activity in the cerebral cortex and hippocampus and a reduction in acetylcholinesterase in these regions. These declines parallel the loss of neurons in these areas. The decline in choline acetyltransferase occurs in the pre-encephalitic stage of bornaviral infection prior to $\mathrm{T}$ cell infiltration into the brains (Gies et al., 1998).

BoDV-1 also affects the dopamine system. Neonatal rats experimentally infected with BoDV-1 develop a hyperactive movement disorder (Solbrig et al., 1996). Since locomotor activity is regulated through the dopamine system, Solbrig et al. examined the dopamine receptors in these rats (Solbrig et al., 1996). They found that there was reduced binding to several dopamine receptors in the nucleus accumbens. The nucleus accumbens is the site where the limbic system and motor information interact. It plays a role in motivational, appetite and locomotor behaviors. Bornaviral-induced alterations have also been recorded in other neurotransmitters such as cholecystokinin and somatostatin (de la Torre, 2002).

\section{Conclusions}

The diversity of clinical manifestations of BoDV-1 infections reflect its complex pathogenicity. Even the development of acute encephalitis reflects the results of multiple disturbances in many neuronal and immune pathways. There appear to be three primary mechanisms involved in this pathology, namely $\mathrm{T}$ cell cytotoxicity; microglial release of inflammatory cytokines and ROS; and astrocyte-induced disturbances in glutaminergic signaling. It is unlikely however that these are the only important pathways involved in the disease process. Thus it is recognized that bornaviruses disrupt the NF-kB pathway (Makino et al., 2015), the RIG-1/MAVS pathway (Reuter et al., 2010) as well as HMGB-1 signaling (Kamitani et al., 2001) and can cause epigenetic changes (Liu et al., 2015). These effects collectively permit the virus to survive innate immune attack and contribute to the disease process. Even in the absence of acute encephalitis BoDV-1 has a profound effect on neurodevelopmental pathways in neonatal rats. This may be of relevance to neurodevelopmental disease in humans.
During the 1990s, interest in BoDV-1 peaked as a result of assertions that it was an unusually common infection in humans with neuropsychiatric disorders. This claim has been refuted. Nevertheless, given the diversity of molecular and epigenetic changes mediated by bornaviruses in mammalian brains, it is conceivable that they can induce alterations in brain function well short of the lethal encephalitis observed in squirrel breeders. It is perhaps time to reopen the investigation into possible links between bornaviral infection and mental illness.

\section{References}

Ackermann A, Guelzow T, Staeheli P, Schneider U and Heimrich B (2010). Visualizing viral dissemination in the mouse nervous system, using a green fluorescent protein-expressing Borna disease virus vector. Journal of Virology 84: 5438-5442.

Amor S, Peferoen LA, Vogel DY, Breur M, Van Der Valk P, Baker D and Van NOORT JM (2014). Inflammation in neurodegenerative diseases-an update. Immunology 142: 151-166.

Amsterdam JD, Winokur A, Dyson W, Herzog S, Gonzalez F, Rott R and Koprowski $H$ (1985). Borna disease virus. A possible etiologic factor in human affective disorders? Archives of General Psychiatry 42: 1093-1096.

Ashash E, Malkinson M, Meir R, Perl S and Weisman Y (1996). Causes of losses including a Borna disease paralytic syndrome affecting young ostriches of one breeding organization over a five-year period (1989-1993). Avian Diseases 40: 240-245.

Bajramovic JJ, Munter S, Syan S, Nehrbass U, Brahic M and GonzalezDunia D (2003). Borna disease virus glycoprotein is required for viral dissemination in neurons. Journal of Virology 77: 12222-12231.

Baruch K and Schwartz M (2013). CNS-specific T cells shape brain function via the choroid plexus. "Brain, Behavior, and Immunity" 34: 11-16.

Bautista JR, Rubin SA, Moran TH, Schwartz GJ and Carbone KM (1995). Developmental injury to the cerebellum following perinatal Borna disease virus infection. Brain Research Developmental Brain Research 90: 45-53.

Berg AL, Johannisson A, Johansson M, Hein A, Berg M and Dorries R (1999). Peripheral and intracerebral $\mathrm{T}$ cell immune response in cats naturally infected with Borna disease virus. Veterinary Immunology and Immunopathology 68: 241-253.

Berg M, Johansson M, Montell H and Berg AL (2001). Wild birds as a possible natural reservoir of Borna disease virus. Epidemiology and Infection 127: 173-178.

Billaud JN, Ly C, Phillips TR and de la Torre JC (2000). Borna disease virus persistence causes inhibition of glutamate uptake by feline primary cortical astrocytes. Journal of Virology 74: 10438-10446.

Bilzer T, Grabner A and Stitz L (1996). Immunopathology of Borna disease in the horse: clinical, virological and neuropathologic findings. Tieraratl Prax 24: 567-576.

Bode L and Ludwig H (2003). Borna disease virus infection, a human mental-health risk. Clinical Microbiology Reviews 16: 534-545.

Bode L, Durrwald R and Ludwig H (1994). Borna virus infections in cattle associated with fatal neurological disease. Veterinary Record 135: 283-284.

Bondy SC and Purdy JL (1977). Putative neurotransmitters of the avian visual pathway. Brain Research 119: 417-426.

Bordey A and Sontheimer H (2003). Modulation of glutamatergic transmission by bergmann glial cells in rat cerebellum in situ. Journal of Neurophysiology 89: 979-988.

Caplazi P and Ehrensperger F (1998). Spontaneous Borna disease in sheep and horses: immunophenotyping of inflammatory cells and detection of MHC-I and MHC-II antigen expression in Borna encephalitis lesions. Veterinary Immunology and Immunopathology 61: 203-220 
Caplazi P, Waldvogel A, Stitz L, Braun U and Ehrensperger F (1994). Borna disease in naturally infected cattle. Journal of Comparative Pathology 111: 65-72.

Carbone KM, Duchala CS, Griffin JW, Kincaid AL and Narayan O (1987). Pathogenesis of Borna disease in rats: evidence that intra-axonal spread is the major route for virus dissemination and the determinant for disease incubation. Journal of Virology 61: 3431-3440.

Carbone KM, Moench TR and Lipkin WI (1991). Borna disease virus replicates in astrocytes, Schwann cells and ependymal cells in persistently infected rats: location of viral genomic and messenger RNAs by in situ hybridization. Journal of Neuropathology and Experimental Neurology 50: 205-214.

Carbone KM, Rubin SA, Nishino Y and Pletnikov MV (2001). Borna disease: virus-induced neurobehavioral disease pathogenesis. Current Opinion in Microbiology 4: 467-475.

Chen J and Kriegstein AR (2015). A GABAergic projection from the zona incerta to cortex promotes cortical neuron development. Science 350: 554-558.

Choi DW (1988). Glutamate neurotoxicity and diseases of the nervous system. Neuron 1: 623-634.

Clemente R, Sisman E, Aza-Blanc P and de la Torre JC (2010). Identification of host factors involved in borna disease virus cell entry through a small interfering RNA functional genetic screen. Journal of Virology 84: 3562-3575.

Coulter DA and Eid T (2012). Astrocytic regulation of glutamate homeostasis in epilepsy. Glia 60: 1215-1226.

Cubitt B, Oldstone C, Valcarcel J and Carlos de la Torre J (1994). RNA splicing contributes to the generation of mature mRNAs of Borna disease virus, a non-segmented negative strand RNA virus. Virus Research 34: 69-79.

de la Torre JC (2002). Bornavirus and the brain. Journal of Infectious Diseases 186 (suppl. 2): S241-S247.

Dietz DM and Pletnikov MV (2003). Postnatal weight gain inhibition does not account for neurobehavioral consequences of neonatal Borna disease virus infection. Physiology \& Behavior 80: 359-366.

Dietzel J, Kuhrt H, Stahl T, Kacza J, Seeger J, Weber M, Uhlig A, Reichenbach A, Grosche A and Pannicke T (2007). Morphometric analysis of the retina from horses infected with the Borna disease virus. Veterinary Pathology 44: 57-63.

Durrwald R and Ludwig H (1997). Borna disease virus (BDV), a (zoonotic?) worldwide pathogen. A review of the history of the disease and the virus infection with comprehensive bibliography. Zentralbl Veterinarmed B 44: 147-184.

Durrwald R, Kolodziejek J, Herzog S and Nowotny N (2007). Metaanalysis of putative human bornavirus sequences fails to provide evidence implicating Borna disease virus in mental illness. Reviews in Medical Virology 17: 181-203.

Durrwald R, Kolodziejek J, Weissenbock H and Nowotny N (2014). The bicolored white-toothed shrew Crocidura leucodon (HERMANN 1780) is an indigenous host of mammalian Borna disease virus. PLOS ONE 9: e93659.

Eisenman LM, Brothers R, Tran MH, Kean RB, Dickson GM, Dietzschold B and Hooper DC (1999). Neonatal Borna disease virus infection in the rat causes a loss of Purkinje cells in the cerebellum. Journal of Neurovirology 5: 181-189.

Enbergs HK, Vahlenkamp TW, Kipar A and Muller H (2001). Experimental infection of mice with Borna disease virus (BDV): replication and distribution of the virus after intracerebral infection. Journal of Neurovirology 7: 272-277.

Engert F and Bonhoeffer T (1999). Dendritic spine changes associated with hippocampal long-term synaptic plasticity. Nature 399: 66-70.

Formella S, Jehle C, Sauder C, Staeheli P and Schwemmle M (2000). Sequence variability of Borna disease virus: resistance to superinfection may contribute to high genome stability in persistently infected cells. Journal of Virology 74: 7878-7883.

Fu ZF, Amsterdam JD, Kao M, Shankar V, Koprowski H and Dietzschold B (1993). Detection of Borna disease virus-reactive antibodies from patients with affective disorders by western immunoblot technique. Journal of Affective Disorders 27: 61-68.

Ganor Y and Levite M (2014). The neurotransmitter glutamate and human T cells: glutamate receptors and glutamate-induced direct and potent effects on normal human $\mathrm{T}$ cells, cancerous human leukemia and lymphoma $\mathrm{T}$ cells, and autoimmune human $\mathrm{T}$ cells. Journal of Neural Transmission 121: 983-1006.

Gies U, Bilzer T, Stitz L and Staiger JF (1998). Disturbance of the cortical cholinergic innervation in Borna disease prior to encephalitis. Brain Pathology 8: 39-48.

Gies U, Gorcs TJ, Mulder J, Planz O, Stitz L, Bilzer T, Luiten PG and Harkany $\mathrm{T}$ (2001). Cortical cholinergic decline parallels the progression of Borna virus encephalitis. Neuroreport 12: 3767-3772.

Gonzalez H, Elgueta D, Montoya A and Pacheco R (2014). Neuroimmune regulation of microglial activity involved in neuroinflammation and neurodegenerative diseases. Journal of Neuroimmunology 274: 1-13.

Gonzalez-Dunia D, Cubitt B and de la Torre JC (1998). Mechanism of Borna disease virus entry into cells. Journal of Virology 72: 783-788.

Gonzalez-Dunia D, Watanabe M, Syan S, Mallory M, Masliah E and de la Torre JC (2000). Synaptic pathology in Borna disease virus persistent infection. Journal of Virology 74: 3441-3448.

Gonzalez-Dunia D, Volmer R, Mayer D and Schwemmle M (2005). Borna disease virus interference with neuronal plasticity. Virus Research 111: 224-234.

Gosztonyi G (2008). Natural and experimental Borna disease virus infections--neuropathology and pathogenetic considerations. APMIS. Supplementum 124: 53-57.

Gosztonyi G and Ludwig H (1984). Borna disease of horses. An immunohistological and virological study of naturally infected animals. Acta Neuropathologica 64: 213-221.

Gosztonyi $G$ and Ludwig H (1995). Borna disease-neuropathology and pathogenesis. Current Topics in Microbiology and Immunology 190: 39-73.

Gosztonyi G, Dietzschold B, Kao M, Rupprecht CE, Ludwig H and Koprowski H (1993). Rabies and borna disease. A comparative pathogenetic study of two neurovirulent agents. Laboratory Investigation 68: 285-295.

Gudino-Cabrera G, Urena-Guerrero ME, Rivera-Cervantes MC, FeriaVelasco AI and Beas-Zarate C (2014). Excitotoxicity triggered by neonatal monosodium glutamate treatment and blood-brain barrier function. Archives of Medical Research 45: 653-659.

Hallensleben W, Schwemmle M, Hausmann J, Stitz L, Volk B, Pagenstecher A and Staeheli P (1998). Borna disease virus-induced neurological disorder in mice: infection of neonates results in immunopathology. Journal of Virology 72: 4379-4386.

Hans A, Bajramovic JJ, Syan S, Perret E, Dunia I, Brahic M and Gonzalez-Dunia D (2004). Persistent, noncytolytic infection of neurons by Borna disease virus interferes with ERK 1/2 signaling and abrogates BDNF-induced synaptogenesis. Faseb Journal 18: 863-865.

Hatalski CG, Hickey WF and Lipkin WI (1998). Evolution of the immune response in the central nervous system following infection with Borna disease virus. Journal of Neuroimmunology 90: $137-142$

Hausmann J, Hallensleben W, de la Torre JC, Pagenstecher A, Zimmermann C, Pircher $\mathrm{H}$ and Staeheli P (1999). T cell ignorance in mice to Borna disease virus can be overcome by peripheral expression of the viral nucleoprotein. Proceedings of the National Academy of Sciences of the United States of America 96: 9769-9774.

Hausmann J, Sauder C, Wasmer M, Lu B and Staeheli P (2004). Neurological disorder after Borna disease virus infection in the absence of either interferon-gamma, Fas, inducible NO synthase, or chemokine receptor CXCR3. Viral Immunology 17: 79-85.

Heneka MT, Kummer MP and Latz E (2014). Innate immune activation in neurodegenerative disease. Nature Reviews. Immunology 14: 463-477.

Herden C, Herzog S, Richt JA, Nesseler A, Christ M, Failing K and Frese K (2000). Distribution of Borna disease virus in the brain 
of rats infected with an obesity-inducing virus strain. Brain Pathology 10: 39-48.

Herden C, Schluesener HJ and Richt JA (2005). Expression of allograft inflammatory factor- 1 and haeme oxygenase- 1 in brains of rats infected with the neurotropic Borna disease virus. Neuropathology and Applied Neurobiology 31: 512-521.

Herzog S, Kompter C, Frese K and Rott R (1984). Replication of Borna disease virus in rats: age-dependent differences in tissue distribution. Medical Microbiology and Immunology 173: 171-177.

Herzog S, Wonigeit K, Frese K, Hedrich HJ and Rott R (1985). Effect of Borna disease virus infection on athymic rats. Journal of General Virology 66 (Pt 3): 503-508.

Hirano N, Kao M and Ludwig H (1983). Persistent, tolerant or subacute infection in Borna disease virus-infected rats. Journal of General Virology 64 (Pt 7): 1521-1530.

Hoffmann B, Tappe D, Hoper D, Herden C, Boldt A, Mawrin C, Niederstrasser $O$, Muller T, Jenckel M, Van Der Grinten E, Lutter C, Abendroth B, Teifke JP, Cadar D, Schmidt-Chanasit J, Ulrich RG and Beer M (2015). A variegated squirrel bornavirus associated with fatal human encephalitis. New England Journal of Medicine 373: 154-162.

Honda T and Tomonaga K (2013). Nucleocytoplasmic shuttling of viral proteins in borna disease virus infection. Viruses 5: 19781990.

Honda T, Fujino K, Okuzaki D, Ohtaki N, Matsumoto Y, Horie M, Daito T, Itoh M and Tomonaga K (2011). Upregulation of insulin-like growth factor binding protein 3 in astrocytes of transgenic mice that express Borna disease virus phosphoprotein. Journal of Virology 85: 4567-4571.

Honkavuori KS, Shivaprasad HL, Williams BL, Quan PL, Hornig M, Street C, Palacios G, Hutchison SK, Franca M, Egholm M, Briese T and Lipkin WI (2008). Novel borna virus in psittacine birds with proventricular dilatation disease. Emerging Infectious Diseases 14: 1883-1886.

Horie M, Honda T, Suzuki Y, Kobayashi Y, Daito T, Oshida T, Ikuta K, Jern P, Gojobori T, Coffin JM and Tomonaga K (2010). Endogenous non-retroviral RNA virus elements in mammalian genomes. Nature 463: 84-87.

Horie M, Kobayashi Y, Suzuki Y and Tomonaga K (2013). Comprehensive analysis of endogenous bornavirus-like elements in eukaryote genomes. "Philosophical Transactions of the Royal Society of London. Series B, Biological Sciences" 368: 20120499.

Hornig M, Weissenbock H, Horscroft N and Lipkin WI (1999). An infection-based model of neurodevelopmental damage. Proceedings of the National Academy of Sciences of the United States of America 96: 12102-12107.

Hornig M, Solbrig M, Horscroft N, Weissenbock H and Lipkin WI (2001). Borna disease virus infection of adult and neonatal rats: models for neuropsychiatric disease. Current Topics in Microbiology and Immunology 253: 157-177.

Hornig M, Briese T, Licinio J, Khabbaz RF, Altshuler LL, Potkin SG, Schwemmle M, Siemetzki U, Mintz J, Honkavuori K, Kraemer HC, Egan MF, Whybrow PC, Bunney WE and Lipkin WI (2012). Absence of evidence for bornavirus infection in schizophrenia, bipolar disorder and major depressive disorder. Molecular Psychiatry 17: 486-493.

Iandiev I, Biedermann B, Bringmann A, Reichel MB, Reichenbach A and Pannicke T (2006). Atypical gliosis in Muller cells of the slowly degenerating rds mutant mouse retina. Experimental Eye Research 82: 449-457.

Jacobs CM, Aden P, Mathisen GH, Khuong E, Gaarder M, Loberg EM, Lomo J, Maehlen J and Paulsen RE (2006). Chicken cerebellar granule neurons rapidly develop excitotoxicity in culture. Journal of Neuroscience Methods 156: 129-135.

Jacobsen B, Algermissen D, Schaudien D, Venner M, Herzog S, Wentz E, Hewicker-Trautwein M, Baumgartner W and Herden C (2010). Borna disease in an adult alpaca stallion (Lama pacos). Journal of Comparative Pathology 143: 203-208.
Jamali T, Jamali Y, Mehrbod M and Mofrad MR (2011). Nuclear pore complex: biochemistry and biophysics of nucleocytoplasmic transport in health and disease. International Review of Cell and Molecular Biology 287: 233-286.

Jarius S and Wildemann B (2015). 'Medusa head ataxia': the expanding spectrum of Purkinje cell antibodies in autoimmune cerebellar ataxia. Part 3: Anti-Yo/CDR2, anti-Nb/AP3B2, PCA-2, anti$\mathrm{Tr} / \mathrm{DNER}$, other antibodies, diagnostic pitfalls, summary and outlook. Journal of Neuroinflammation 12: 168.

Johnson RT (1980). Selective vulnerability of neural cells to viral infections. Brain 103: 447-472.

Kacza J, Vahlenkamp TW, Enbergs H, Richt JA, Germer A, Kuhrt H, Reichenbach A, Muller H, Herden C, Stahl T and Seeger J (2000). Neuron-glia interactions in the rat retina infected by Borna disease virus. Archives of Virology 145: 127-147.

Kacza J, Mohr C, Pannicke T, Kuhrt H, Dietzel J, Fluss M, Richt JA, Vahlenkamp TW, Stahl T, Reichenbach A and Seeger J (2001). Changes of the organotypic retinal organization in Borna virusinfected Lewis rats. Journal of Neurocytology 30: 801-820.

Kamitani W, Shoya Y, Kobayashi T, Watanabe M, Lee BJ, Zhang G, Tomonaga K and Ikuta K (2001). Borna disease virus phosphoprotein binds a neurite outgrowth factor, amphoterin/HMG-1. Journal of Virology 75: 8742-8751.

Kamitani W, Ono E, Yoshino S, Kobayashi T, Taharaguchi S, Lee BJ, Yamashita M, Kobayashi T, Okamoto M, Taniyama H, Tomonaga K and Ikuta K (2003). Glial expression of Borna disease virus phosphoprotein induces behavioral and neurological abnormalities in transgenic mice. Proceedings of the National Academy of Sciences of the United States of America 100: 8969-8974.

Kao M, Ludwig H and Gosztonyi G (1984). Adaptation of Borna disease virus to the mouse. Journal of General Virology 65 (Pt 10): 1845-1849.

Katsumoto A, Lu H, Miranda AS and Ransohoff RM (2014). Ontogeny and functions of central nervous system macrophages. Journal of Immunology 193: 2615-2621.

Kinnunen PM, Billich C, Ek-Kommonen C, Henttonen H, Kallio RK, Niemimaa J, Palva A, Staeheli P, Vaheri A and Vapalahti O (2007). Serological evidence for Borna disease virus infection in humans, wild rodents and other vertebrates in Finland. Journal of Clinical Virology 38: 64-69.

Kinnunen PM, Palva A, Vaheri A and Vapalahti O (2013). Epidemiology and host spectrum of Borna disease virus infections. Journal of General Virology 94: 247-262.

Kistler AL, Gancz A, Clubb S, Skewes-Cox P, Fischer K, Sorber K, Chiu CY, Lublin A, Mechani S, Farnoushi Y, Greninger A, Wen CC, Karlene SB, Ganem D and Derisi JL (2008). Recovery of divergent avian bornaviruses from cases of proventricular dilatation disease: identification of a candidate etiologic agent. Virology Journal 5: 88.

Krey H, Ludwig H and Rott R (1979). Spread of infectious virus along the optic nerve into the retina in Borna disease virus-infected rabbits. Archives of Virology 61: 283-288.

Krey H, Ludwig H and Gierend M (1981). Borna disease virus-induced retinouveitis treated with immunosuppressive drugs. Albrecht Von Graefes Arch Klin Exp Ophthalmol 216: 111-119.

Kuhn J, Dürrwald R, Bào Y, Briese T, Carbone K, Clawson A, Derisi J, Garten W, Jahrling P, Kolodziejek J, Rubbenstroth D, Schwemmle M, Stenglein M, Tomonaga K, Weissenböck H and Nowotny N (2015). Taxonomic reorganization of the family Bornaviridae. Archives of Virology 160: 621-632.

Lancaster K, Dietz DM, Moran TH and Pletnikov MV (2007). Abnormal social behaviors in young and adult rats neonatally infected with Borna disease virus. Behavioural Brain Research 176: 141-148.

Lee BJ, Watanabe M, Kamitani W, Baba S, Yamashita M, Kobayashi T, Tomonaga K and Ikuta K (2003). Age- and host-dependent control of Borna disease virus spread in the developing brains of gerbils and rats. Microbes and Infection 5: 1195-1204. 
Lennartz F, Bayer K, Czerwonka N, Lu Y, Kehr K, Hirz M, Steinmetzer T, Garten W and Herden C (2016). Surface glycoprotein of Borna disease virus mediates virus spread from cell to cell. Cellular Microbiology 18: 340-354.

Levite M (2008). Neurotransmitters activate T-cells and elicit crucial functions via neurotransmitter receptors. Current Opinion in Pharmacology 8: 460-471.

Lipkin WI, Briese T and Hornig M (2011). Borna disease virus - fact and fantasy. Virus Research 162: 162-172.

Liu X, Liu S, Bode L, Liu C, Zhang L, Wang X, Li D, Lei Y, Peng X, Cheng $Z$ and Xie P (2015). Persistent human Borna disease virus infection modifies the acetylome of human oligodendroglia cells towards higher energy and transporter levels. Virology 485: 58-78.

Ludwig H (2008). The biology of bornavirus. APMIS. Supplementum 124: 14-20.

Ludwig H and Bode L (2000). Borna disease virus: new aspects on infection, disease, diagnosis and epidemiology. Revue Scientifique et Technique 19: 259-288.

Lundgren AL, Lindberg R, Ludwig H and Gosztonyi G (1995a). Immunoreactivity of the central nervous system in cats with a Borna disease-like meningoencephalomyelitis (staggering disease). Acta Neuropathologica 90: 184-193.

Lundgren AL, Zimmermann W, Bode L, Czech G, Gosztonyi G, Lindberg R and Ludwig H (1995b). Staggering disease in cats: isolation and characterization of the feline Borna disease virus. Journal of General Virology 76 (Pt 9): 2215-2222.

Lundgren AL, Johannisson A, Zimmermann W, Bode L, Rozell B, Muluneh A, Lindberg R and Ludwig H (1997). Neurological disease and encephalitis in cats experimentally infected with Borna disease virus. Acta Neuropathologica 93: 391-401.

Lutz H, Addie DD, Boucraut-Baralon C, Egberink H, Frymus T, Gruffydd-Jones T, Hartmann K, Horzinek MC, Hosie MJ, Lloret A, Marsilio F, Pennisi MG, Radford AD, Thiry E, Truyen U and Mostl K (2015). Borna disease virus infection in cats: ABCD guidelines on prevention and management. Journal of Feline Medicine and Surgery 17: 614-616.

Lyons MJ, Nagashima K and Zabriskie JB (2002). Animal models of postinfectious obesity: hypothesis and review. Journal of Neurovirology 8: 1-5.

Makino A, Fujino K, Parrish NF, Honda T and Tomonaga K (2015). Borna disease virus possesses an NF-kB inhibitory sequence in the nucleoprotein gene. Scientific Reports 5: 8696.

Malkinson M, Weisman Y, Ashash E, Bode L and Ludwig H (1993). Borna disease in ostriches. Veterinary Record 133: 304.

Matsumoto Y, Hayashi Y, Omori H, Honda T, Daito T, Horie M, Ikuta K, Fujino K, Nakamura S, Schneider U, Chase G, Yoshimori T, Schwemmle M and Tomonaga K (2012). Bornavirus closely associates and segregates with host chromosomes to ensure persistent intranuclear infection. Cell Host \& Microbe 11: 492-503.

Metzler A, Frei U and Danner K (1976). Virologically confirmed outbreak of Borna's disease in a Swiss herd of sheep. Schweizer Arcbiv fur Tierbeilleunde 118: 483-492.

Metzler A, Minder HP, Wegmann C and Zindel W (1979). Borna disease, a veterinary problem of regional significance. Schweizer Archiv fur Tierheilkunde 121: 207-213.

Morales JA, Herzog S, Kompter C, Frese K and Rott R (1988). Axonal transport of Borna disease virus along olfactory pathways in spontaneously and experimentally infected rats. Medical Microbiology and Immunology 177: 51-68.

Morimoto K, Hooper DC, Bornhorst A, Corisdeo S, Bette M, Fu ZF, Schafer MK, Koprowski H, Weihe E and Dietzschold B (1996). Intrinsic responses to Borna disease virus infection of the central nervous system. Proceedings of the National Academy of Sciences of the United States of America 93: 13345-13350.

Nagashima K, Zabriskie JB and Lyons MJ (1992). Virus-induced obesity in mice: association with a hypothalamic lesion. Journal of Neuropathology and Experimental Neurology 51: 101-109.

Nakamura Y, Nakaya T, Hagiwara K, Momiyama N, Kagawa Y, Taniyama H, Ishihara C, Sata T, Kurata T and Ikuta K (1999).
High susceptibility of Mongolian gerbil (Meriones unguiculatus) to Borna disease virus. Vaccine 17: 480-489.

Narayan O, Herzog S, Frese K, Scheefers H and Rott R (1983a). Behavioral disease in rats caused by immunopathological responses to persistent borna virus in the brain. Science 220: 1401-1403.

Narayan O, Herzog S, Frese K, Scheefers H and Rott R (1983b). Pathogenesis of Borna disease in rats: immune-mediated viral ophthalmoencephalopathy causing blindness and behavioral abnormalities. Journal of Infectious Diseases 148: 305-315.

Nishino Y, Ooishi R, Kurokawa S, Fujino K, Murakami M, Madarame H, Hashimoto O, Sugiyama K and Funaba M (2009). Gene expression of the TGF-beta family in rat brain infected with Borna disease virus. Microbes and Infection 11: 737-743.

Nishino Y, Murakami M and Funaba M (2015). Expression and role of the TGF-beta family in glial cells infected with Borna disease virus. Microbes and Infection 18: 128-136.

Nobach D, Bourg M, Herzog S, Lange-Herbst H, Encarnacao JA, Eickmann M and Herden C (2015). Shedding of Infectious Borna Disease Virus-1 in Living Bicolored White-Toothed Shrews. PLoS ONE 10: e0137018.

Noske K, Bilzer T, Planz O and Stitz L (1998). Virus-specific CD4+ T cells eliminate Borna disease virus from the brain via induction of cytotoxic CD8+ T cells. Journal of Virology 72: 4387-4395.

Nouri M, Bredberg A, Westrom B and Lavasani S (2014). Intestinal barrier dysfunction develops at the onset of experimental autoimmune encephalomyelitis, and can be induced by adoptive transfer of auto-reactive T cells. PLoS ONE 9: e106335.

Okamoto M, Kagawa Y, Kamitani W, Hagiwara K, Kirisawa R, Iwai H, Ikuta $\mathrm{K}$ and Taniyama $\mathrm{H}$ (2002). Borna disease in a dog in Japan. Journal of Comparative Pathology 126: 312-317.

Ovanesov MV, Sauder C, Rubin SA, Richt J, Nath A, Carbone KM and Pletnikov MV (2006). Activation of microglia by borna disease virus infection: in vitro study. Journal of Virology 80: 12141-12148.

Ovanesov MV, Vogel MW, Moran TH and Pletnikov MV (2007). Neonatal Borna disease virus infection in rats is associated with increased extracellular levels of glutamate and neurodegeneration in the striatum. Journal of Neurovirology 13: 185-194.

Ovanesov MV, Ayhan Y, Wolbert C, Moldovan K, Sauder C and Pletnikov MV (2008a). Astrocytes play a key role in activation of microglia by persistent Borna disease virus infection. Journal of Neuroinflammation 5: 50.

Ovanesov MV, Moldovan K, Smith K, Vogel MW and Pletnikov MV (2008b). Persistent Borna Disease Virus (BDV) infection activates microglia prior to a detectable loss of granule cells in the hippocampus. Journal of Neuroinflammation 5: 16.

Pacheco R, Riquelme E and Kalergis AM (2010). Emerging evidence for the role of neurotransmitters in the modulation of $\mathrm{T}$ cell responses to cognate ligands. Central Nervous System Agents in Medicinal Chemistry 10: 65-83.

Papageorgiou IE, Lewen A, Galow LV, Cesetti T, Scheffel J, Regen T, Hanisch UK and Kann O (2015). TLR4-activated microglia require IFN-gamma to induce severe neuronal dysfunction and death in situ. Proceedings of the National Academy of Sciences of the United States of America 113: 212-217.

Peng G, Yan Y, Zhu C, Wang S, Yan X, Lu L, Li W, Hu J, Wei W, Mu Y, Chen Y, Feng Y, Gong R, Wu K, Zhang F, Zhang X, Zhu Y and Wu J (2008). Borna disease virus $P$ protein affects neural transmission through interactions with gamma-aminobutyric acid receptor-associated protein. Journal of Virology 82: 1248712497.

Pikor NB, Astarita JL, Summers-Deluca L, Galicia G, Qu J, Ward LA, Armstrong S, Dominguez CX, Malhotra D, Heiden B, Kay R, Castanov V, Touil H, Boon L, O'CONNOR P, Bar-Or A, Prat A, Ramaglia V, Ludwin S, Turley SJ and Gommerman JL (2015). Integration of Th17- and Lymphotoxin-derived signals initiates meningeal-resident stromal cell remodeling to propagate Neuroinflammation. Immunity 43: 1160-1173. 
Planz O, Bilzer T, Sobbe M and Stitz L (1993). Lysis of major histocompatibility complex class I-bearing cells in Borna disease virus-induced degenerative encephalopathy. Journal of Experimental Medicine 178: 163-174.

Planz O, Dumrese T, Hulpusch S, Schirle M, Stevanovic S and Stitz L (2001). A naturally processed rat major histocompatibility complex class I-associated viral peptide as target structure of borna disease virus-specific CD8+ T cells. Journal of Biological Chemistry 276: 13689-13694.

Plata-Salaman CR, Ilyin SE, Gayle D, Romanovitch A and Carbone KM (1999). Persistent Borna disease virus infection of neonatal rats causes brain regional changes of mRNAs for cytokines, cytokine receptor components and neuropeptides. Brain Research Bulletin 49: 441-451.

Pletnikov MV, Rubin SA, Vogel MW, Moran TH and Carbone KM (2002). Effects of genetic background on neonatal Borna disease virus infection-induced neurodevelopmental damage. II. Neurochemical alterations and responses to pharmacological treatments. Brain Research 944: 108-123.

Puorger ME, Hilbe M, Muller JP, Kolodziejek J, Nowotny N, Zlinszky $\mathrm{K}$ and Ehrensperger F (2010). Distribution of Borna disease virus antigen and RNA in tissues of naturally infected bicolored whitetoothed shrews, Crocidura leucodon, supporting their role as reservoir host species. Veterinary Pathology 47: 236-244.

Reuter A, Ackermann A, Kothlow S, Rinder M, Kaspers B and Staeheli P (2010). Avian bornaviruses escape recognition by the innate immune system. Viruses 2: 927-938.

Richt JA and Rott R (2001). Borna disease virus: a mystery as an emerging zoonotic pathogen. Veterinary Journal 161: 24-40.

Richt JA, Vandewoude S, Zink MC, Clements JE, Herzog S, Stitz L, Rott R and Narayan O (1992). Infection with Borna disease virus: molecular and immunobiological characterization of the agent. Clinical Infectious Diseases 14: 1240-1250.

Richt JA, Pfeuffer I, Christ M, Frese K, Bechter K and Herzog S (1997). Borna disease virus infection in animals and humans. Emerging Infectious Diseases 3: 343-352.

Richt JA, Grabner A and Herzog S (2000). Borna disease in horses. The Veterinary Clinics of North America. Equine Practice 16: 579-595, xi.

Richter K, Hausmann J and Staeheli P (2009). Interferon-gamma prevents death of bystander neurons during CD8 $\mathrm{T}$ cell responses in the brain. American Journal of Pathology 174: 1799-1807.

Rossi D and Volterra A (2009). Astrocytic dysfunction: insights on the role in neurodegeneration. Brain Research Bulletin 80: 224-232.

Rott R and Becht H (1995). Natural and experimental Borna disease in animals. Current Topics in Microbiology and Immunology 190: 17-30.

Rott R, Herzog S, Fleischer B, Winokur A, Amsterdam J, Dyson W and Koprowski H (1985). Detection of serum antibodies to Borna disease virus in patients with psychiatric disorders. Science 228: $755-756$.

Rott R, Herzog S, Richt J and Stitz L (1988). Immune-mediated pathogenesis of Borna disease. Zentralbl Bakteriol Mikrobiol Hyg A 270: 295-301.

Rubbenstroth D, Schmidt V, Rinder M, Legler M, Corman VM and Staeheli P (2014). Discovery of a new avian bornavirus genotype in estrildid finches (Estrildidae) in Germany. Veterinary Microbiology 168: 318-323.

Rubin SA, Waltrip RW II, Bautista JR and Carbone KM (1993). Borna disease virus in mice: host-specific differences in disease expression. Journal of Virology 67: 548-552.

Russo MV and Mcgavern DB (2015). Immune surveillance of the CNS following infection and injury. Trends in Immunology 36: 637-650.

Salinas S, Schiavo G and Kremer EJ (2010). A hitchhiker's guide to the nervous system: the complex journey of viruses and toxins. Nature Reviens. Microbiology 8: 645-655.

Sauder C and de la Torre JC (1999). Cytokine expression in the rat central nervous system following perinatal Borna disease virus infection. Journal of Neuroimmunology 96: 29-45.
Sauder C and Staeheli P (2003). Rat model of borna disease virus transmission: epidemiological implications. Journal of V irology 77: 12886-12890.

Schneemann A, Schneider PA, Kim S and Lipkin WI (1994). Identification of signal sequences that control transcription of borna disease virus, a nonsegmented, negative-strand RNA virus. Journal of Virology 68: 6514-6522.

Schneider PA, Schneemann A and Lipkin WI (1994). RNA splicing in Borna disease virus, a nonsegmented, negative-strand RNA virus. Journal of Virology 68: 5007-5012.

Schwartz M, Shaked I, Fisher J, Mizrahi T and Schori H (2003). Protective autoimmunity against the enemy within: fighting glutamate toxicity. Trends in Neurosciences 26: 297-302.

Schwemmle M, Salvatore M, Shi L, Richt J, Lee CH and Lipkin WI (1998). Interactions of the borna disease virus $\mathrm{P}, \mathrm{N}$, and $\mathrm{X}$ proteins and their functional implications. Journal of Biological Chemistry 273: 9007-9012.

Scordel C, Huttin A, Cochet-Bernoin M, Szelechowski M, Poulet A, Richardson J, Benchoua A, Gonzalez-Dunia D, Eloit M and Coulpier M (2015). Borna disease virus phosphoprotein impairs the developmental program controlling neurogenesis and reduces human GABAergic neurogenesis. PLoS Pathogens 11: e1004859.

Sobbe M, Bilzer T, Gommel S, Noske K, Planz O and Stitz L (1997). Induction of degenerative brain lesions after adoptive transfer of brain lymphocytes from Borna disease virus-infected rats: presence of CD8+ T cells and perforin mRNA. Journal of Virology 71: 2400-2407.

Solbrig MV and Koob GF (2003). Neuropharmacological sequelae of persistent CNS viral infections: lessons from Borna disease virus. "Pharmacology, Biochemistry, and Behavior" 74: 777-787.

Solbrig MV, Koob GF, Joyce JN and Lipkin WI (1996). A neural substrate of hyperactivity in borna disease: changes in brain dopamine receptors. Virology 222: 332-338.

Sprankel H, Richarz K, Ludwig H and Rott R (1978). Behavior alterations in tree shrews (Tupaia glis, Diard 1820) induced by Borna disease virus. Medical Microbiology and Immunology 165: 1-18.

Staeheli P, Sauder C, Hausmann J, Ehrensperger F and Schwemmle M (2000). Epidemiology of Borna disease virus. Journal of General Virology 81: 2123-2135.

Stahl T, Mohr C, Kacza J, Reimers C, Pannicke T, Sauder C, Reichenbach A and Seeger J (2003). Characterization of the acute immune response in the retina of Borna disease virus infected Lewis rats. Journal of Neuroimmunology 137: 67-78.

Stitz L, Krey H and Ludwig H (1981). Borna disease in rhesus monkeys as a models for uveo-cerebral symptoms. Journal of Medical Virology 6: $333-340$

Stitz L, Soeder D, Deschl U, Frese K and Rott R (1989). Inhibition of immune-mediated meningoencephalitis in persistently Borna disease virus-infected rats by cyclosporine A. Journal of Immunology 143: 4250-4256.

Stitz L, Schilken D and Frese K (1991). Atypical dissemination of the highly neurotropic Borna disease virus during persistent infection in cyclosporine A-treated, immunosuppressed rats. Journal of Virology 65: 457-460.

Stitz L, Sobbe M and Bilzer T (1992). Preventive effects of early antiCD4 or anti-CD8 treatment on Borna disease in rats. Journal of Virology 66: 3316-3323.

Stitz L, Noske K, Planz O, Furrer E, Lipkin WI and Bilzer T (1998). A functional role for neutralizing antibodies in Borna disease: influence on virus tropism outside the central nervous system. Journal of Virology 72: 8884-8892.

Stitz L, Bilzer T and Planz O (2002). The immunopathogenesis of Borna disease virus infection. Frontiers in Bioscience 7: d541-d555.

Takeuchi H, Jin S, Wang J, Zhang G, Kawanokuchi J, Kuno R, Sonobe Y, Mizuno T and Suzumura A (2006). Tumor necrosis factoralpha induces neurotoxicity via glutamate release from hemichannels of activated microglia in an autocrine manner. Journal of Biological Chemistry 281: 21362-21368. 
Tomonaga K, Kobayashi T and Ikuta K (2002). Molecular and cellular biology of Borna disease virus infection. Microbes and Infection 4: 491-500.

Vahlenkamp TW, Konrath A, Weber M and Muller H (2002). Persistence of Borna disease virus in naturally infected sheep. Journal of Virology 76: 9735-9743.

Vesce S, Rossi D, Brambilla L and Volterra A (2007). Glutamate release from astrocytes in physiological conditions and in neurodegenerative disorders characterized by neuroinflammation. International Review of Neurobiology 82: 57-71.

Volmer R, Prat CM, Le Masson G, Garenne A and Gonzalez-Dunia D (2007). Borna disease virus infection impairs synaptic plasticity. Journal of Virology 81: 8833-8837.

Waelchli RO, Ehrensperger F, Metzler A and Winder C (1985). Borna disease in a sheep. Veterinary Record 117: 499-500.

Walsh JT, Watson N and Kipnis J (2014). T cells in the central nervous system: messengers of destruction or purveyors of protection? Immunology 141: 340-344.

Watanabe M, Lee BJ, Kamitani W, Kobayashi T, Taniyama H, Tomonaga K and Ikuta K (2001). Neurological diseases and viral dynamics in the brains of neonatally borna disease virusinfected gerbils. Virology 282: 65-76.

Watanabe M, Lee BJ, Yamashita M, Kamitani W, Kobayashi T, Tomonaga K and Ikuta K (2003). Borna disease virus induces acute fatal neurological disorders in neonatal gerbils without virusand immune-mediated cell destructions. Virology 310: 245-253.

Weissenbock H, Nowotny N, Caplazi P, Kolodziejek J and Ehrensperger F (1998). Borna disease in a dog with lethal meningoencephalitis. Journal of Clinical Microbiology 36: 2127-2130.

Weissenbock H, Hornig M, Hickey WF and Lipkin WI (2000). Microglial activation and neuronal apoptosis in Bornavirus infected neonatal Lewis rats. Brain Pathology 10: 260-272.

Wensman JJ, Ilback C, Hjertstrom E, Blomstrom AL, Gustavsson MH, Jaderlund KH, Strom-Holst B, Belak S, Berg AL and Berg M
(2011). Expression of interferon gamma in the brain of cats with natural Borna disease virus infection. Veterinary Immunology and Immunopathology 141: 162-167.

Wensman JJ, Jaderlund KH, Gustavsson MH, Hansson-Hamlin H, Karlstam E, Lilliehook I, Ostrom IL, Belak S, Berg M and Holst BS (2012). Markers of Borna disease virus infection in cats with staggering disease. Journal of Feline Medicine and Surgery 14: 573-582.

Wensman JJ, Jaderlund KH, Holst BS and Berg M (2014). Borna disease virus infection in cats. Veterinary Journal 201: 142-149.

Wu YJ, Schulz H, Lin CC, Saar K, Patone G, Fischer H, Hubner N, Heimrich B and Schwemmle M (2013). Borna disease virusinduced neuronal degeneration dependent on host genetic background and prevented by soluble factors. Proceedings of the National Academy of Sciences of the United States of America 110: 1899-1904.

Zhang L, Lei Y, Liu X, Wang X, Liu Z, Li D, Zheng P, Zhang L, Chen $S$ and Xie P (2014). Glutamate and lipid metabolic perturbation in the hippocampi of asymptomatic borna disease virus-infected horses. PLOS ONE 9: e99752.

Zheng YM, Schafer MK, Weihe E, Sheng H, Corisdeo S, Fu ZF, Koprowski H and Dietzschold B (1993). Severity of neurological signs and degree of inflammatory lesions in the brains of rats with Borna disease correlate with the induction of nitric oxide synthase. Journal of Virology 67: 5786-5791.

Zimmermann W, Breter H, Rudolph M and Ludwig H (1994). Borna disease virus: immunoelectron microscopic characterization of cell-free virus and further information about the genome. Journal of Virology 68: 6755-6758.

Zocher M, Czub S, Schulte-Monting J, de la Torre JC and Sauder C (2000). Alterations in neurotrophin and neurotrophin receptor gene expression patterns in the rat central nervous system following perinatal Borna disease virus infection. Journal of Neurovirology $\mathbf{6}$ : $462-477$. 